OPEN ACCESS

Edited by:

Takayuki Yoshimoto,

Tokyo Medical University, Japan

Reviewed by:

Marko Radic

University of Tennessee College of

Medicine, United States

Harumichi Ishigame,

RIKEN, Japan

*Correspondence:

Adnana Paunel-Görgülü adnana.paunel-goerguelue@ uk-koeln.de

Specialty section:

This article was submitted to

Inflammation,

a section of the journa

Frontiers in Immunology

Received: 26 June 2019 Accepted: 12 September 2019

Published: 01 October 2019

Citation:

Eghbalzadeh K, Georgi L, Louis T,

Zhao H, Keser U, Weber $C$ Mollenhauer M, Conforti A, Wahlers T

and Paunel-Görgülü A (2019)

Compromised Anti-inflammatory Action of Neutrophil Extracellular Traps in PAD4-Deficient Mice Contributes to Aggravated Acute Inflammation After

Myocardial Infarction.

Front. Immunol. 10:2313.

doi: 10.3389/fimmu.2019.02313

\section{Compromised Anti-inflammatory Action of Neutrophil Extracellular Traps in PAD4-Deficient Mice Contributes to Aggravated Acute Inflammation After Myocardial Infarction}

Kaveh Eghbalzadeh ${ }^{1}$, Leena Georgi ${ }^{1}$, Theresa Louis ${ }^{1}$, Haizhi Zhao ${ }^{1}$, Ugur Keser ${ }^{1}$, Carolyn Weber ${ }^{1}$, Martin Mollenhauer ${ }^{2,3}$, Andreas Conforti ${ }^{1}$, Thorsten Wahlers ${ }^{1}$ and Adnana Paunel-Görgülü ${ }^{1 *}$

\footnotetext{
${ }^{1}$ Department of Cardiothoracic Surgery, Heart Center, University of Cologne, Cologne, Germany, ${ }^{2}$ Department of Cardiology, Heart Center, University of Cologne, Cologne, Germany, ${ }^{3}$ Center for Molecular Medicine Cologne, University of Cologne, Cologne, Germany
}

Innate immune responses and rapid recruitment of leukocytes, which regulate inflammation and subsequent healing, play a key role in acute myocardial infarction (MI). Peptidylarginine deiminase 4 (PAD4) is critically involved in chromatin decondensation during the release of Neutrophil Extracellular Traps (NETs) by activated neutrophils. Alternatively, activated macrophages (M2) and accurate collagen deposition determine the repair of the infarcted heart. In this study, we investigated the impact of NETs on macrophage polarization and their role for acute cardiac inflammation and subsequent cardiac healing in a mouse model of acute MI. NETs were found to promote in vitro macrophage polarization toward a reparative phenotype. NETs suppressed pro-inflammatory macrophages (M1) under hypoxia and diminished IL-6 and TNF- $\alpha$ expression. Further on, NETs strongly supported M2b polarization and IL-10 expression. In cardiac fibroblasts, NETs increased TGF- $B$ expression under hypoxic culture conditions. PAD4 ${ }^{-1-}$ mice subjected to permanent ligation of the left anterior descending artery suffered from overwhelming inflammation in the acute phase of MI. Noteworthy, PAD4-/- neutrophils were unable to release NETs upon ex vivo stimulation with ionomycin or PMA, but produced significantly higher amounts of reactive oxygen species (ROS). Increased levels of circulating cell-free DNA, mitochondrial DNA and cardiac troponin were found in PAD4 ${ }^{-/-}$mice in the acute phase of Ml when compared to WT mice. Reduced cardiac expression of IL-6, IL-10, and M2 marker genes, as well as increased TNF- $\alpha$ expression, suggested a pro-inflammatory state. PAD4 ${ }^{-/}$- mice displayed significantly increased cardiac MMP-2 expression under baseline conditions. At day 1, post-MI, PAD4-/- mice showed increased end-diastolic volume and increased thinning of the left ventricular wall. Interestingly, improved cardiac function, as demonstrated by significantly increased ejection fraction, was found at day 
21. Altogether, our results indicate that NETs support macrophage polarization toward an M2 phenotype, thus displaying anti-inflammatory properties. PAD4 deficiency aggravates acute inflammation and increases tissue damage post-MI, partially due to the lack of NETs.

Keywords: neutrophil extracellular traps, inflammation, PAD4, myocardial infarction, macrophages

\section{INTRODUCTION}

Myocardial infarction (MI) leads to the death of up to one billion cardiac cells in response to occurred ischemia and, in consequence, the affected myocardium undergoes a series of remodeling processes accompanied by inflammatory responses, fibrosis and finally scar formation (1). Infarct healing and subsequent remodeling might lead to impaired cardiac function resulting in chronic heart failure, a major cause of high morbidity and mortality (2). Thus, healing of the infarcted heart substantially affects patients' outcome and, therefore, regulation of this process might offer a potential therapeutic strategy for patients suffering from MI. During the first hours after MI, neutrophils massively infiltrate into the infarct area and release cytokines and chemokines, as well as reactive oxygen species (ROS), which exacerbate vascular and tissue injury. Moreover, activated neutrophils release decondensated chromatin covered by elastase, myeloperoxidase (MPO) and cytoplasmic proteins, known as neutrophil extracellular traps (NETs). This process of NETs formation is called NETosis and largely differs from apoptosis and necrosis. Although NETs may contribute to the clearance of bacteria during infection, they are additionally involved in many pathological conditions, such as deep vein thrombosis (3), ischemia/reperfusion (4), atherosclerosis (5), cancer and trauma $(6,7)$, amongst others. Formation of NETs strongly depends on the enzyme peptidylarginine deiminase 4 (PAD4), which citrullinates arginine residues on histone tails resulting in chromatin decondensation. Accordingly, PAD4-deficient mice were shown to lack NETosis yielding in significant protection from myocardial ischemia reperfusion injury (4). Similarly, increased neutrophil counts are prognostic for larger infarct size (8) and depletion of neutrophils in a canine ischemic reperfusion model was shown to reduce infarct size (9). A recent study has demonstrated that, beside neutrophils, monocytes become rapidly recruited after ischemia onset (10). Monocytes/macrophages exhibit high phenotypic and functional plasticity and several macrophage phenotypes have already been described. At early times with a peak around day 3 , macrophages are polarized to pro-inflammatory M1 macrophages, whereas over time, a shift to alternatively activated M2 cells occurs, which promote resolution of inflammation and tissue remodeling (11). M2 macrophages were subdivided into M2a, M2b, and M2c cells according to their functional properties and activation mechanisms. M2a and M2c cells are crucial for promoting the adaptive immune response and clearance of apoptotic cells (12), whereas, M2b cells are largely involved in the suppression and regulation of inflammation by the secretion of high levels of IL-10 (13). Impaired resolution of inflammation and prolonged M1 macrophage activation may aid adverse cardiac remodeling and impair MI outcomes. In this regard, silencing of interferon regulatory factor 5 (IRF5), which regulates polarization toward the M1 phenotype, shifted macrophage phenotype from M1 to M2 in the heart and attenuated heart failure post-MI (14).

It is widely known that fibroblasts are critically involved in the reparative response following MI and are implicated in the pathogenesis of cardiac remodeling (15). Injury induces fibroblast proliferation, migration to the injured areas and transdifferentiation into myofibroblasts, which express contractile proteins such as $\alpha$ - smooth muscle actin and might contribute to cardiac fibrosis. Myofibroblasts produce large amounts of collagens, which are crucial for preventing rupture of the ventricular wall. Whereas, ROS and transforming growth factor- $\beta$ (TGF- $\beta$ ) signaling have been reported to play a major role in fibroblast activation, recently. Fibroblasts were demonstrated to undergo transdifferentiating to collagen-producing myofibroblasts after incubation with NETs in vitro, and NETs were found in proximity to $\alpha$-smooth muscle actin ( $\alpha$-SMA)-positive fibroblasts in tissue sections from patients with fibrotic intestinal lung disease (16). Hence, pro-fibrotic signals secreted at the infarction site might be involved in the development of reactive fibrosis in the noninfarcted myocardium (17). Whether NETs contribute to adverse remodeling has not been investigated so far. Further on, although activated neutrophils and macrophages interact closely in the infarcted heart, nothing is known about the effect of NETs regarding macrophage polarization and, thus, about their immunoregulatory properties. In the present study, we therefore aimed to explore the effects of NETs on macrophage polarization and acute inflammation and to further prove their effects on cardiac regeneration post-MI using an established acute MI model.

\section{MATERIALS AND METHODS}

\section{Animals}

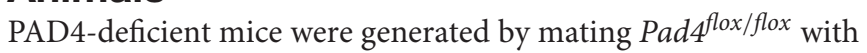
$\mathrm{Tg}(\mathrm{CMV}$-Cre $) 1 \mathrm{Cgn}$ mice to delete exons 9-10. All mice were obtained from the Jackson laboratory. C57BL/6J wildtype mice served as controls. Mice were housed at $22-24^{\circ} \mathrm{C}$ in a $12 / 12 \mathrm{~h}$ light/dark cycle and given free access to water and standard rodent chow. Experiments on mice were performed at 9-12 weeks of age. All animal studies were reviewed and approved by the local animal care committee (Landesamtes für Natur, Umwelt und Verbraucherschutz (LANUV), Germany, No.8402.04.2014.A234) and were in accordance with the Guide for the care and Use of Laboratory Animals. 


\section{Induction of MI}

MI was induced by permanent ligation of the left anterior descending coronary artery (LAD). Before surgery, buprenorphine $(0.1 \mathrm{mg} / \mathrm{kg})$ was administered s.c. Male WT and $\mathrm{PAD}^{-/-}$were anesthetized with $2 \%$ isoflurane, then intubated and ventilated with a standard rodent ventilator (MiniVent Ventilator for Mice, Harvard Apparatus). The thoracic cavity was opened and the LAD was ligated with $8 / 0$ polypropylene suture placed through the myocardium into the anterolateral LV wall. Sham operated animals were subjected to thoracotomy without LAD ligation. Infarction was confirmed by echocardiography and Evans blue staining of excised hearts.

\section{Quantification of Infarct Size}

Mice were sacrificed at the end of experiment and hearts were excised and cut into four 2-mm sliced. Each section was incubated in 1\% 2,3,5-triphenyltetrazolium chloride (TTC, Sigma-Aldrich) solution for $15 \mathrm{~min}$ at $37^{\circ} \mathrm{C}$. Both sides of each TTC-stained tissue slice were photographed using a digital camera. Infarct size is expressed as a percentage of total left ventricular mass.

\section{Echocardiographic Analyses}

Transthoracic echocardiography was performed with a Vevo 3100 (VisualSonics, Inc., Toronto, ON, Canada) system. Mice were maintained under anesthesia with continuously delivered $2 \%$ isoflurane gas inhalation and additional s.c. buprenorphine application $(0.1 \mathrm{mg} / \mathrm{kg})$. Examination was conducted on a temperature-controlled platform to prevent hypothermia caused by the ultrasound gel and to ensure physiological heart and respiratory rates. Ultrasound gel was applied to the depilated skin of the chest. Imaging was obtained with a MX550d transducer (40 MHz center transmit, axial resolution $40 \mu \mathrm{m}$; VisualSonics, Inc.). Baseline cardiac function was determined in a cohort of healthy non-operated WT and PAD4 ${ }^{-/-}$mice. Sham operated and permanent $\mathrm{LAD}$ ligation cohorts of $\mathrm{WT}$ and $\mathrm{PAD} 4^{-/-}$mice both underwent echocardiographic measurements at days 1,3 , and 21 post-MI. Comprehensive left ventricular function was analyzed as already published elsewhere (18).

\section{Isolation and Polarization of Murine Macrophages}

Bone marrow cells were isolated by flushing femurs of 9-12 weeks old C57/Bl6 mice. Cells $\left(1.7-2 \times 10^{6}\right)$ were cultured in 6-well plates in RPMI medium supplemented with $20 \%$ FCS containing $20 \mathrm{ng} / \mathrm{ml}$ recombinant murine M-CSF (Peprotech), $100 \mathrm{U} / \mathrm{ml}$ penicillin and $10 \mu \mathrm{g} / \mathrm{ml}$ streptomycin (Sigma Aldrich) in a humidified incubator at $37^{\circ} \mathrm{C}$. On days 3 and 6 , the medium was changed. Differentiated macrophages (M0) were obtained after 7 days of culture.

For in vitro polarization, M0 macrophages were cultured in RPMI medium with $10 \%$ FCS supplemented with $20 \mathrm{ng} / \mathrm{ml}$ recombinant murine IFN-r (Peprotech) and $100 \mathrm{ng} / \mathrm{ml}$ LPS (Sigma Aldrich) to induce a M1-like phenotype or in medium supplemented with $20 \mathrm{ng} / \mathrm{ml}$ recombinant murine IL-4 (Peprotech) to induce M2a-like macrophages, respectively.

\section{Isolation of Cardiac Fibroblasts}

Cardiac fibroblasts were isolated from excised hearts of 812 weeks old C57/Bl6J wildtype mice. In brief, heart tissue was cut into small pieces and digested in collagenase II (100 $\mathrm{U} / \mathrm{ml}$ ) and trypsin $(0.2 \%)$ in HBSS at $37^{\circ} \mathrm{C}$ for 30 min using C Tubes (Miltenyi), and following dissociation by gentle MACS Dissociator (Miltenyi). The digested tissue was filtered through a $70 \mu \mathrm{m}$ cell strainer and cells were centrifuged at $300 \times g$ for $5 \mathrm{~min}$ and washed in PBS. Cells were seeded in T75 flasks and the medium was carefully replaced after $2 \mathrm{~h}$. Cells were cultured in DMEM/F12 medium supplemented with $10 \% \mathrm{FCS}$ at $37^{\circ} \mathrm{C}$ and $5 \% \mathrm{CO}_{2}$ and split at a confluency of $\sim 80 \%$. In this study, cardiac fibroblasts at passage 3 have been used.

\section{Isolation of Murine Bone-Marrow Neutrophils}

Neutrophils were isolated from the bone marrow of wildtype C57/Bl6J and PAD4 ${ }^{-/-}$mice. Mice were euthanized, femurs and tibias were flushed with HBSS $+3 \%$ FCS and cells were passed through a $70 \mu \mathrm{m}$ strainer to remove tissue. Red blood cells were hypotonically lysed using $0.2 \% \mathrm{NaCl}$, followed by the addition of $1.2 \% \mathrm{NaCl}$ to stop lysing. Neutrophils were then isolated by density gradient centrifugation using $62 \%$ percoll (GE Healthcare). Cells were gently laid on percoll and centrifuged at $1,000 \times g$ for $30 \mathrm{~min}$ at $15^{\circ} \mathrm{C}$ without break. Neutrophils were found in the pellet and washed twice with HBSS $+3 \%$ FCS.

\section{Cell Culture Conditions}

For cell culture experiments, cells were cultured under normoxia $\left(21 \% \mathrm{O}_{2}, 5 \% \mathrm{CO}_{2}\right)$ at $37^{\circ} \mathrm{C}$ for $20 \mathrm{~h}$. In parallel experiments, cells were placed in a hypoxia chamber (Stem cell technologies) and cultured under hypoxic conditions $\left(2 \% \mathrm{O}_{2}, 5 \% \mathrm{CO}_{2}\right)$ at $37^{\circ} \mathrm{C}$ for equivalent periods of time.

\section{Flow Cytometry}

Hearts excised at day 1 post-MI were digested with collagenase II $(450 \mathrm{U} / \mathrm{ml})$, hyaluronidase type I-S $(60 \mathrm{U} / \mathrm{ml})$ and DNase (60 U/ml) in DMEM, and filtered through a $40 \mu \mathrm{m}$ cell strainer. After lysis of red blood cells (Multi-species RB Lysis Buffer, eBioscience), immune cells were identified by CD45 staining (FITC rat anti-mouse, clone 30-F11, BD). Dead cells were excluded by propidium iodide staining $(1 \mu \mathrm{g} / \mathrm{ml})$ and live singlets were gated by FSC-A/FSC-H. To identify macrophages/monocytes, cells were additionally stained using F4/80 APC (clone BM8, Bio Legend) antibodies and samples were quantified by flow cytometry using MACS Quant Analyzer (Miltenyi Biotec). The percentage of $\mathrm{CD} 45^{+} / \mathrm{F} 4 / 80^{+}$cells was calculated from the total number of vital cells.

\section{In vitro Neutrophil Stimulation and Generation of NETs-Enriched Supernatants}

To induce NETs release, bone marrow-derived neutrophils (4 $\times 10^{6}$ ) were seeded into 6-well culture plates and stimulated with $100 \mathrm{nM}$ phorbol myristate acetate (PMA; Sigma Aldrich) for $3.5 \mathrm{~h}$. In some experiments cells were stimulated with $4 \mu \mathrm{M}$ ionomycin (Cayman Chemicals). For NETs isolation, supernatants were carefully discarded and cells were washed 
once with PBS. PBS was then added and residual neutrophils and NETs were collected by vigorous pipetting. Cell debris were centrifuged at $50 \times g$ for $5 \mathrm{~min}$ at $4^{\circ} \mathrm{C}$ and NETs-enriched supernatants were collected and stored at $-80^{\circ} \mathrm{C}$ until use. DNA/NETs concentration was quantified using a NanoDrop spectrophotometer (Thermo Fisher) at a wavelength of $260 \mathrm{~nm}$.

\section{Determination of Peroxidase Activity in NETs-Enriched Supernatants}

Peroxidase activity in supernatants from simulated neutrophils was measured by mixing a $50 \mu \mathrm{l}$ sample with $50 \mu \mathrm{l}$ detection solution (1:1 TMB Substrate A/TMB Substrate B, BioLegend) in a 96-well plate. After $3 \mathrm{~min}$ incubation at room temperature, the staining reaction was stopped by adding $50 \mu \mathrm{H} \mathrm{H}_{2} \mathrm{SO}_{4}$. The absorbance was measured at $450 \mathrm{~nm}$ using a microplate reader (Victor X3, Perkin Elmer).

\section{Quantification of ROS Production}

To quantify ROS production in neutrophils, freshly isolated neutrophils were suspended in RPMI $+2 \%$ FCS $+2 \mathrm{mM} \mathrm{Ca}^{2+}$ and $3-4 \times 10^{5}$ cells $(200 \mu \mathrm{l})$ were added into 96 well plates and stimulated with different concentrations of ionomycin and PMA for $3 \mathrm{~h}$ at $37^{\circ} \mathrm{C}$. Then, $20 \mu \mathrm{M}$ DHR-123 (PromoKine) was added to the wells and plates were incubated under shaking for $15 \mathrm{~min}$ at $37^{\circ} \mathrm{C}$. Plates were placed on ice and further centrifuged at 1,500 $\mathrm{rpm}$ for $5 \mathrm{~min}$ at $4^{\circ} \mathrm{C}$. Supernatants were removed and cells were washed with PBS. Finally, cells were suspended in $200 \mu \mathrm{l}$ PBS and DHR-123 conversion into the fluorophore rhodamine-123 (R123) was detected at $485 \mathrm{~nm}$ using Victor $\mathrm{X} 3$ microplate reader (Perkin Elmer).

\section{Purification of cfDNA From Plasma}

cfDNA was isolated from plasma samples of WT and PAD4deficient mice at day 1 after MI induction by the method previously described (19).

\section{NETs Induction and Immunofluorescence Staining}

To induce NETosis, freshly isolated bone marrow-derived neutrophils $\left(1.5 \times 10^{5}\right)$ were seeded on poly-L-lysine coated coverslips. Cells were stimulated with $4 \mu \mathrm{M}$ ionomycin for $3 \mathrm{~h}$. After that, cells were fixed with 4\% PFA, blocked and incubated with a polyclonal rabbit anti-myeloperoxidase antibody (1:100, Abcam), or alternatively, with a rabbit anti-histone $\mathrm{H} 3$ (citrulline $\mathrm{R} 2+\mathrm{R} 8+\mathrm{R} 17)$ antibody (1:500, Abcam). Cells were further incubated with a secondary goat anti-rabbit Alexa Fluor 488-conjugated antibody (1:1,000, Cell Signaling Technology), counterstained with DAPI and mounted in Dako fluorescent mounting medium (Dako). NETs were finally visualized using an inverted microscope (Eclipse Ti-U 100, Nikon) and the NIS Elements BR 3.10 software package.

\section{Quantification of NETs and Plasma cfDNA}

Freshly isolated neutrophils were suspended in RPMI $+2 \%$ FCS $+2 \mathrm{mM} \mathrm{Ca}^{2+}$ and $2 \times 10^{5}$ cells $(200 \mu \mathrm{l})$ were added into 96 well plates and stimulated with $4 \mu \mathrm{M}$ ionomycin for $3 \mathrm{~h}$ at $37^{\circ} \mathrm{C}$. Pico Green (Invitrogen) was then added to the wells and plates were incubated for $3 \mathrm{~min}$ in the dark. After plate centrifugation at $50 \times g$ for $5 \mathrm{~min}, 200 \mu \mathrm{l}$ supernatant was carefully transferred into a new plate. Fluorescence intensity was measured in a multiplate reader (Victor X3, Perkin Elmer) at excitation and emission wavelengths of $485 \mathrm{~nm}$ and $530 \mathrm{~nm}$. Culture medium without cells was used as blank control.

cfDNA levels in plasma samples were quantified by Pico Green staining as previously described (19).

\section{Immunoblotting}

Cell lysates were loaded onto acrylamide gels and transferred to nitrocellulose membrane. Membranes were blocked and incubated with the following antibodies according to manufacturer's protocols: polyclonal rabbit anti-mouse Collagen I $\alpha 1$, rabbit anti-mouse Collagen III $\alpha 1$ (both Novus Biologicals) and polyclonal rabbit anti-mouse $B$-Actin, rabbit anti-mouse Smad3, and rabbit monoclonal anti-mouse Phospho-Smad3 (Ser 423/425, clone C25A9) (Cell Signaling Technology).

Membranes were then exposed to anti-rabbit horseradish peroxidase as secondary antibody (Dako), and signal detection was performed using ECL detection reagent (Thermo Fisher).

\section{Real Time PCR}

Total RNA was extracted using RNeasy Mini Kit (Qiagen) or Tri Reagent (Sigma Aldrich) according to the manufacturer's instructions. Contaminating DNA was removed by DNA-free Kit DNA Removal Kit (Ambion). RNA was reverse transcribed using High Capacity cDNA Reverse Transcription Kit (Applied Biosystems). For Real time PCR, gene-specific primers for $i N O S$ (20), Arg I (21), TNF- $\alpha$ (22), IL-10 (23), TGF- $\beta$ (24), MMP-2 (25), MMP-9 (26), Collagen-1, Collagen-3 (27), IL-6, $18 S$ RNA (19), Fizz1/RELM $\alpha$, Ym-1 (28), SPHK1, LIGHT (29), MertK (30), were used. All samples were run in triplicates. Relative gene expression levels were determined using PowerUP SYBR Green PCR Master Mix (Applied Biosystems) according to the manufacturer's recommended protocol with the following thermal cycling conditions: $2 \mathrm{~min} 50^{\circ} \mathrm{C}, 2 \mathrm{~min} 95^{\circ} \mathrm{C}, 40$ cycles of $1 \mathrm{~s} 95^{\circ} \mathrm{C}$ and $30 \mathrm{~s} 60^{\circ} \mathrm{C}$, and $4^{\circ} \mathrm{C}$ hold (QuantStudio 3 Real-Time PCR System, Applied Biosystems). Expression of target genes was normalized to the endogenous control 18S RNA gene. Fold expression was calculated using the $2^{-\Delta \Delta \mathrm{Ct}}$ methods. In some experiments, the $2^{\Delta \mathrm{Ct}}$ method was used to determine relative gene expression.

\section{Mitochondrial DNA Quantification}

The content of mtDNA in plasma was assessed using a specific primer for mouse mtDNA and nuclear B2m (31). Real time PCR was performed using $5 \mathrm{ng}$ of template DNA and $800 \mathrm{nM}$ of each primer. All samples were analyzed in duplicate. The average threshold cycle number $(\mathrm{Ct})$ values were determined in the same quantitative PCR run. The level of mtDNA was calculated relative to nuclear B2m as follows: relative copy number $2^{\Delta \mathrm{Ct}}$, whereby $\Delta \mathrm{Ct}=$ Ctnuc - Ctmit.

\section{ELISAs}

For cytokine quantification in culture supernatants, the following ELISA kits have been used: Human/mouse TGF beta 12 nd 
Generation ELISA Ready-SET-Go (eBioscience), Mouse IL-6 DuoSet ELISA (R\&D Systems), Mouse IL-10 DuoSet ELISA (R\&D Systems) and Mouse TNF alpha ELISA Ready-SET-Go (eBioscience) following the manufacturers' instructions. Cardiac troponin (cTnT) was quantified using Mouse cTnT/TNNT2 ELISA Kit (Immunoway).

A mouse multiplex Immunoassay (ProcartaPlex 4 Plex, Thermo Fisher) and Luminex 200 System (Thermo Fisher) were used to quantify cytokines in plasma samples.

\section{Statistical Analyses}

Data were analyzed with GraphPad Prism 5 software. Experimental data are presented as means with standard error of the mean (SEM). Datasets were assessed for normality using the Kolmogorov-Smirnov test. Unpaired data of two groups were analyzed using unpaired $t$-test. Normally distributed unpaired data of multiple groups were analyzed using one-way ANOVA with Newman Keuls post-hoc test. In cases of non-normal distribution, Mann-Whitney was used. $P$-value less that 0.05 was considered as statistically significant.

\section{RESULTS}

\section{NETs Alter Macrophage Phenotype and Enhance IL-10 Expression in vitro}

Cardiac healing following MI involves inflammation and tissue remodeling. Macrophage polarization has recently been recognized to define resolution of inflammation and the quality of cardiac healing (32). NETs have for a long time been considered to possess pro-inflammatory actions. We, therefore, investigated the impact of NETs for the inflammatory response to $\mathrm{MI}$ in respect to their ability to influence macrophage phenotype in vitro. To this end, we used NETs-enriched supernatants from in vitro activated bone marrow-derived neutrophils. Initial experiments performed to estimate the proper concentration of NETs demonstrated that, at a concentration of $1,000 \mathrm{ng} / \mathrm{ml}$, NETs induce significant differences between control and NETstreated group. Bone marrow-derived macrophages from WT mice were stimulated with 1,000 ng/ml NETs under M1- (IFN$\mathrm{r}+$ LPS) or M2a (IL-4)-polarizing culture conditions. To imitate ischemia in the infarcted heart, cells were cultured under hypoxic condition $\left(2 \% \mathrm{O}_{2}\right)$ and cells cultured under normoxia $\left(21 \% \mathrm{O}_{2}\right)$ served as a control. In the presence of IFN-y and LPS and hypoxic conditions, NETs significantly suppressed inducible nitric oxide synthase (iNOS), IL-6 and TNF- $\alpha$ gene expression and slightly upregulated $\operatorname{Arg} I$ expression, which is a marker of the M2 phenotype (Figure 1A). Of note, $I L-10$ expression was significantly upregulated. Accordingly, reduced IL- 6 and TNF- $\alpha$ levels and increased IL-10 secretion could be observed (Figure 1B).

Under M2a-polarizing conditions, NETs suppressed iNOS and matrix metalloproteinase (MMP)-9 expression (Figure 1C). MMP-9 has been reported to be upregulated in macrophages after IL-4 stimulation (33). In turn, upregulation of arginase I ( $\mathrm{Arg}$ I) and $I L-10$ gene and IL-10 protein expression were detected (Figures 1C,D). Although NETs exerted more pronounced effects under hypoxia, IL-10 was also strongly regulated under normoxic conditions, indicating that NETs might modulate macrophage IL-10 expression in the non-ischemic myocardium.

To verify if IL-10 indeed becomes regulated by NETs, in some experiments, macrophages cultured under normoxic conditions were treated with NETs pre-digested with DNase I and supernatant collected from ionomycin-stimulated PAD4 $4^{-/-}$ neutrophils, respectively, which were shown to be unable to release NETs (34). As shown in Figure 1E, NETs-mediated effects could not be reproduced with digested DNA or DNA released by $\mathrm{PAD} 4^{-/-}$cells, due to other cell death mechanisms which differ from NETosis. These results suggest that NETs release post-MI may drive macrophage polarization toward an antiinflammatory phenotype.

Because NETs obviously promote M2 polarization under proand anti-inflammatory culture conditions, we next investigated if NETs favor polarization toward one of the three macrophage subpopulations, termed M2a, M2b, and M2c. Treatment with NETs under M1-polarizing conditions and hypoxia upregulated the M2b marker SPHK1 but suppressed the M2c marker MertK (Figure 2A). Similarly, we also observed upregulation of the M2b marker LIGHT under M2a-polarizing conditions. In addition, downregulation of the M2a marker genes, Ym-1, and Fizz/RELM$\alpha$, could be detected, indicating suppression of wound healing and fibrosis markers (Figure 2B).

The backbone of NETs mainly consists of chromatin, which in turn includes histone proteins, DNA and nucleosomes. All of these components have been described to exert different immunomodulatory effects (35). To find out whether gene regulation at least partially depends on NETs-triggered pathways, we next performed Toll-like receptor 9 (TLR-9) blocking experiments. As NETs were found to strongly suppress $I L-6$ and to increase $I L-10$ expression under M1-polarizing conditions, as well as to strongly upregulate $I L-10$ and LIGHT under M2apolarizing conditions (Figures 1, 2), we chose these genes to elaborate whether TLR-9 is involved in NETs-induced signaling pathways. Inhibition of endosomal acidification by chloroquine did not influence NETs-mediated down-regulation of $I L-6$ expression, suggesting that this cytokine is not regulated by DNA, but rather by other NETs components. On the contrary, no upregulation of $I L-10$ under M1-polarizing conditions, as well as $I L-10$ and LIGHT under M2a-polarizing conditions, could be observed after blockage of TLR-9 (Supplementary Figure 1). Similar results were obtained when IL-10 was detected in culture supernatants (data not shown). Thus, regulation of $I L-10$ and LIGHT expression by NETs occurs via TLR-9 signaling.

\section{NETs Influence the Activity of Cardiac Fibroblasts in vitro}

Cardiac fibroblasts are critically involved in both reparative and fibrotic processes and their activity determines cardiac healing and remodeling in distinct ways. Excessive proliferation and profibrotic activity might favor adverse remodeling and cardiac fibrosis (36). To determine whether NETs regulate fibrosisrelated factors, we additionally treated cardiac fibroblasts with NETs under hypoxia and normoxia (Figure 3). NETs significantly increased TGF- $\beta$ mRNA expression in cardiac fibroblasts 


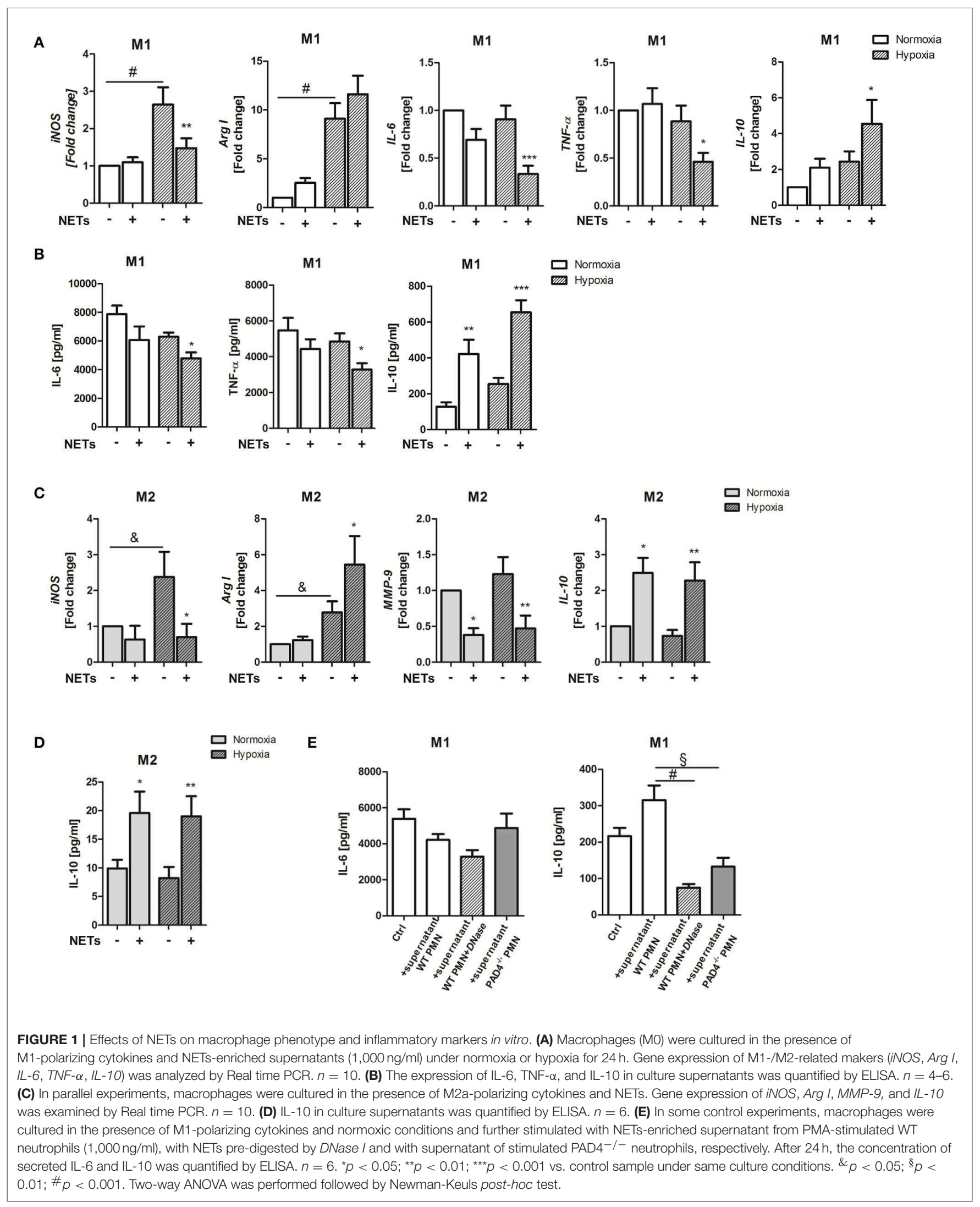


A

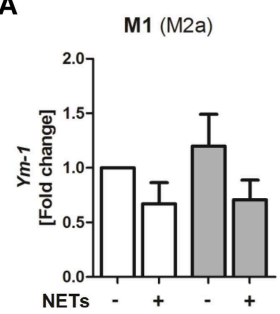

B

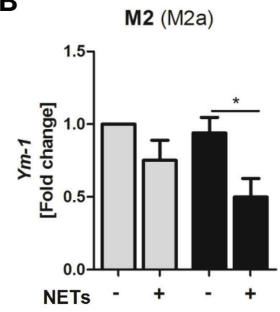

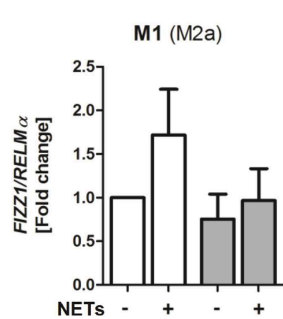

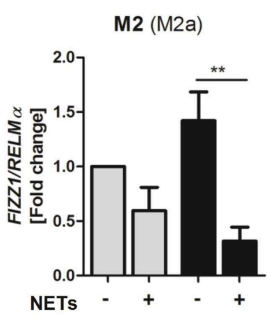

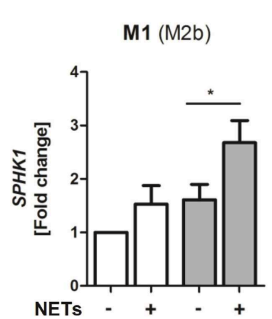
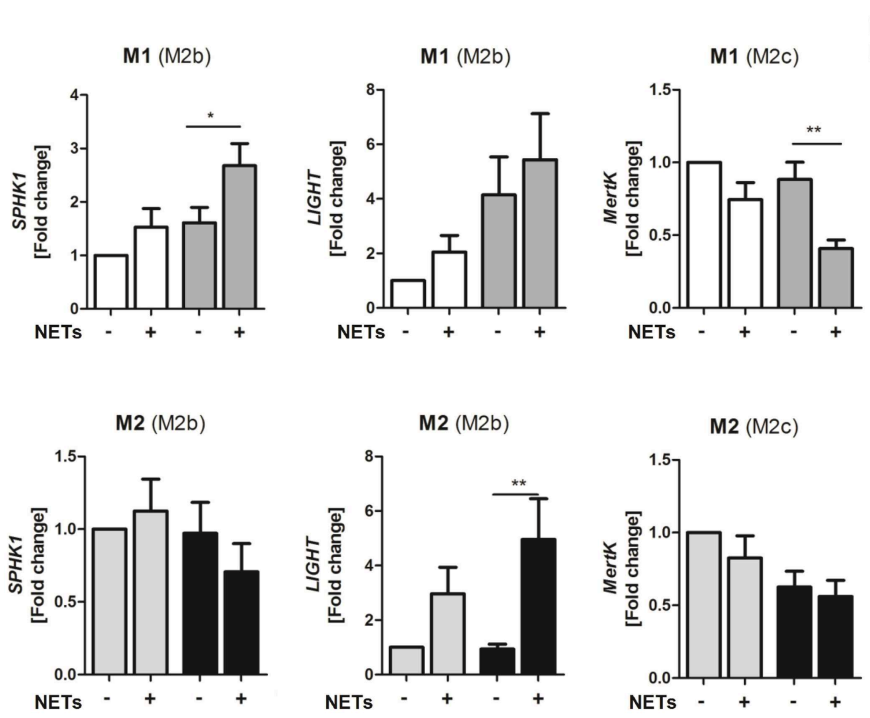

FIGURE 2 | NETs promote upregulation of M2b marker genes in vitro. Macrophages (M0) were cultured in the presence of M1- (A) or M2a- (B) polarizing cytokines and 1,000 ng/ml NETs under normoxia or hypoxia for $24 \mathrm{~h}$. Marker genes specific for the M2a (Ym1, Fizz1/RELM $)$, M2b (SPHK1, LIGHT), and M2c (MertK) subtypes were analyzed by Real time PCR. $n=8-10 .{ }^{*} p<0.05 ;{ }^{* *} p<0.01$. Two-way ANOVA was performed followed by Newman-Keuls post-hoc test.

cultured under hypoxic conditions. MMP-2 expression, which is associated with adverse remodeling (37), did not change, whereas, significant collagen-1 and -3 suppression was found to occur after incubation with NETs under normoxic conditions. NETs also reduced collagen-3, but not collagen-1, expression under hypoxic conditions (Figure 3A). Although TGF-ß protein secretion by fibroblasts was found to be slightly upregulated by NETs (Figure 3B), we observed an inhibition of collagen1 and-3 protein expression under normoxic, but not under hypoxic culture conditions (Figure 3C). No regulation of the $\alpha$ SMA gene and protein expression was detected (data not shown).

\section{Neutrophils From PAD4-Deficient Mice Are Unable to Release NETs but Produce Higher Levels of ROS}

To test whether bone marrow-derived neutrophils from $\mathrm{PAD}^{-/-}$mice are able to release NETs we stimulated cells with the calcium ionophore ionomycin, which induces hyperactivation of PADs and protein citrullination. As depicted in Figure 4, only WT neutrophils formed NETs (Figure 4A) and released cfDNA in culture supernatants (Figure 4B) upon stimulation, whereas NETs formation was abrogated in the absence of functional PAD4. Similarly, stimulation of WT neutrophils with PMA provoked NETs release (Figure 4C), correlating with upregulated peroxidase activity in culture supernatants (Figure 4D). On the contrary, only diminished peroxidase activity was measured in supernatants of PAD4 ${ }^{-/-}$ neutrophils incubated with ionomycin and PMA, respectively.

The production of ROS by NADPH oxidase is considered to be a hallmark in the process of NETosis. To find out whether PAD4 deficiency is attributed to altered oxidative burst in leukocytes, we stimulated WT and PAD4 $4^{-/-}$bone marrow-derived neutrophils with different concentrations of PMA and ionomycin and quantified ROS by DHR-123 staining. Of note, cells deficient for active PAD4 produced significantly higher amounts of ROS when compared to WT cells after stimulation with both PMA and ionomycin (Figure 4E). Because PMA is a strong activator of the NADPH oxidase complex, pre-incubation of cells with the NADPH oxidase inhibitor DPI strongly suppressed ROS production. In turn, ionomycin did not stimulate NADPH oxidase activity and no effect of DPI was found. Importantly, higher levels of ROS were found in PAD4 ${ }^{-/-}$neutrophils after ionomycin stimulation, suggesting increased NADPH oxidaseindependent ROS production. Inhibition of PAD4 activity in WT neutrophils by GSK484 significantly increased ROS production upon PMA stimulation (Figure 4F). These results suggest a possible regulation of the NADPH oxidase complex and other intracellular ROS sources by PAD4.

\section{PAD4-Deficient Mice Display Higher Levels of cfDNA, cTnT and Pro-Inflammatory Mediators in the Acute Phase Post-MI}

An increase in cfDNA after $\mathrm{MI}$ is widely believed to be a consequence of MI-associated cell death and neutrophil activation, which release NETs. Having shown that PAD4 ${ }^{-/-}$ neutrophils do not release NETs ex vivo, we next tested if PAD4 deficiency results in diminished cfDNA elevation after MI in mice, and if so, whether these mice display more profound signs of inflammation. Although significant elevation in cfDNA (Figure 5A) and nucleosome levels (Figure 5B) were detected in WT mice at day 1 post-MI, surprisingly, this increase was more prominent in $\mathrm{PAD} 4^{-/-}$mice, and significant 
A
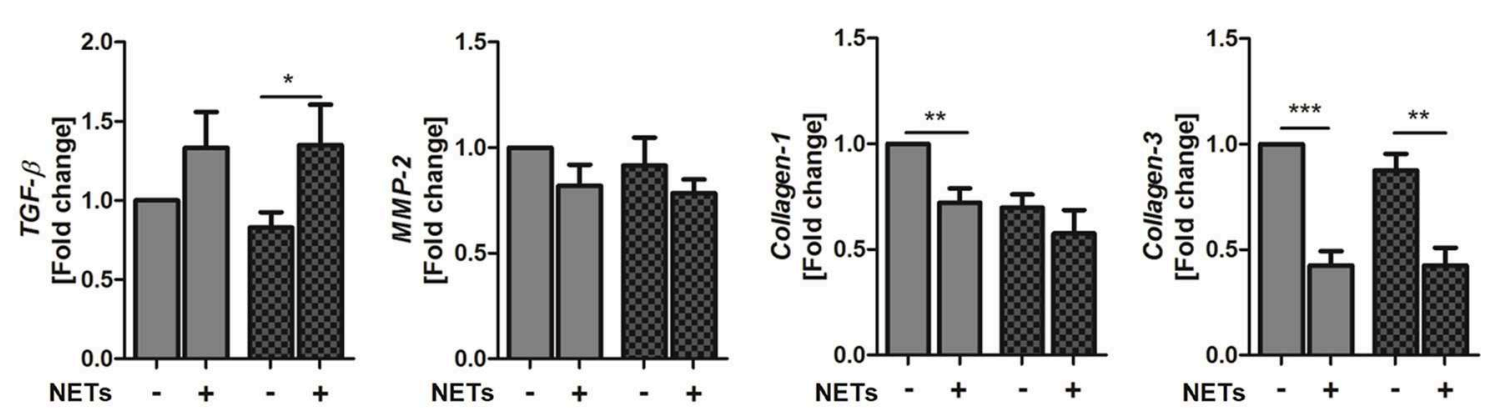

B

C
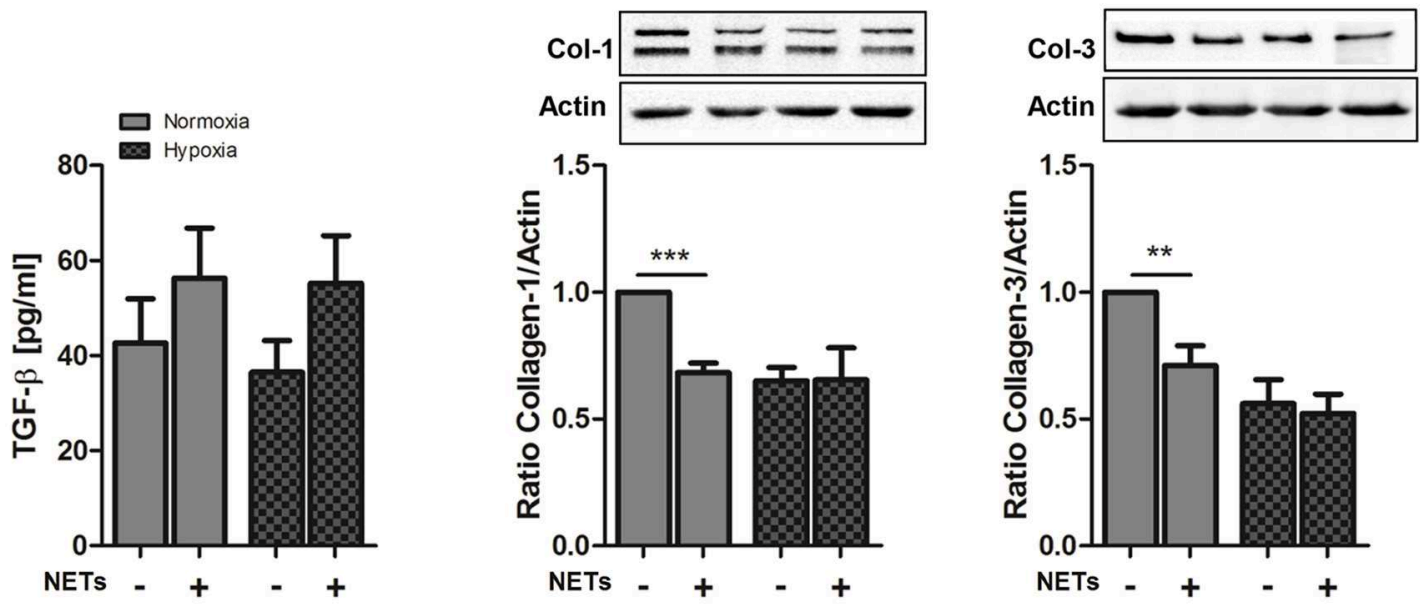

FIGURE 3 | Effect of NETs on collagen expression in cardiac fibroblasts in vitro. Cardiac fibroblasts were stimulated with $1,000 \mathrm{ng} / \mathrm{ml}$ NETs and cultured under normoxic and hypoxic conditions for $24 \mathrm{~h}$. (A) Expression of TGF-B, MMP-2, Collagen-1, and Collagen-3 was evaluated by Real time PCR. $n=10$. (B) TGF- $B$ levels were quantified in culture supernatants. $n=6$. (C) The expression of Collagen-1 and Collagen-3 in cardiac fibroblasts was analyzed by Western blot. $n=65-7$. ${ }^{\star} p<0.05 ;{ }^{* \star} p<0.01 ;{ }^{\star \star \star} p<0.001$. Two-way ANOVA was performed followed by Newman-Keuls post-hoc test.

intergroup differences were found at that time. However, at day 3, nucleosome levels were significantly lower in PAD4 ${ }^{-/-}$ mice compared to WT mice. To address whether enhanced cfDNA release in $\mathrm{PAD}^{-/-}$mice in the acute phase postMI might be due to increased damage of the myocardium, cardiac troponin $\mathrm{T}$ (cTnT) levels in plasma were additionally quantified (Figure 5C). Indeed, in PAD4-deficient mice, cTnT amounts were already significantly elevated at day 1 post-MI and were somehow higher when compared to the amounts detected in WT mice. In contrast, cardiac damage in WT mice was delayed and cTnT levels increased first at day 3 post-MI. In line with this, significantly higher levels of circulating mtDNA were detected in PAD4 ${ }^{-/-}$mice at day 1 supporting the hypothesis that PAD4 deficiency aggravates tissue damage in the acute phase (Figure 5D). Accordingly, increased plasma levels of IL-6, monocyte chemoattractant protein-1 (MCP-1), and TNF- $\alpha$ were found at day 1 and of IFN-r at day 3 post-MI in PAD4 ${ }^{-/-}$mice, respectively (Figure 5E). IL-10 levels remained below detection levels at all time points (not shown).
We next assessed whether circulating cfDNA from PAD4 ${ }^{-/-}$ mice, obviously released by damaged cells, acts different to NETs. For this, macrophages were stimulated with $600 \mathrm{ng} / \mathrm{ml}$ DNA isolated from day 1 plasma of mice subjected to LAD ligation (Figure 5F). Plasma-derived cfDNA from PAD4 $4^{-/-}$ mice strongly increased IL-6 secretion and inhibited IL-10 release by macrophages under M1-polarizing conditions, supporting the pro-inflammatory nature of cfDNA. Importantly, plasmaderived cfDNA from WT mice (day 1) was found to increase IL-10 expression in M1 cells, thus showing NETs-like properties.

\section{Different Cardiac Expression of Inflammation-Related Genes in PAD4-Deficient Mice at Day 1 Post-MI}

To further examine the inflammatory response within infarcted hearts, we quantified the expression of inflammatory genes and macrophage marker genes by Real time PCR. As displayed in Figure 6A, the expression of $I L-6$ and $I L-10$ significantly 
A
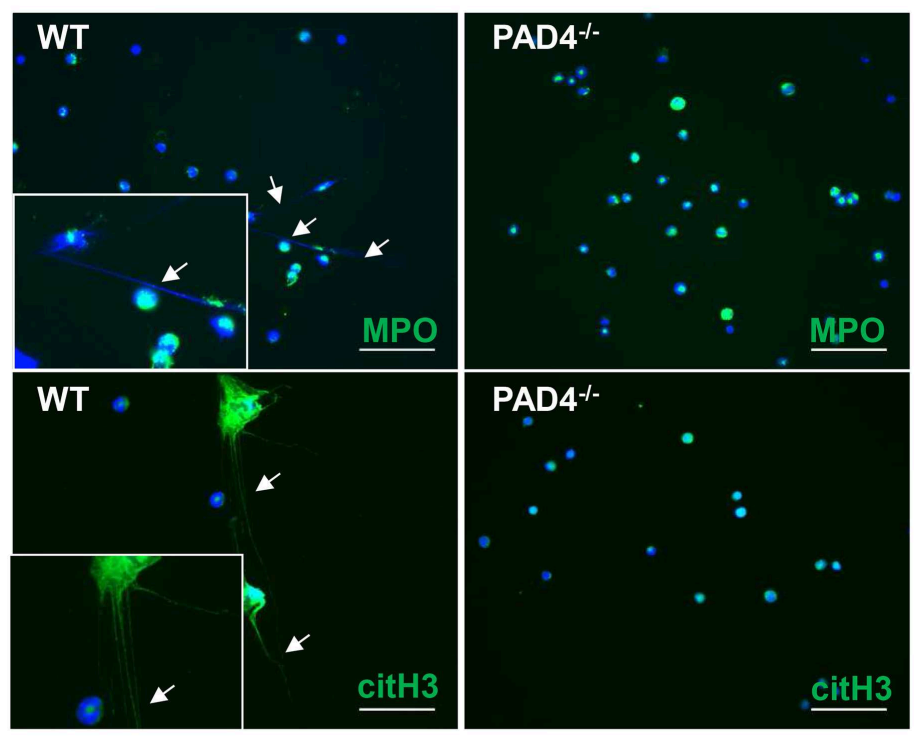

C
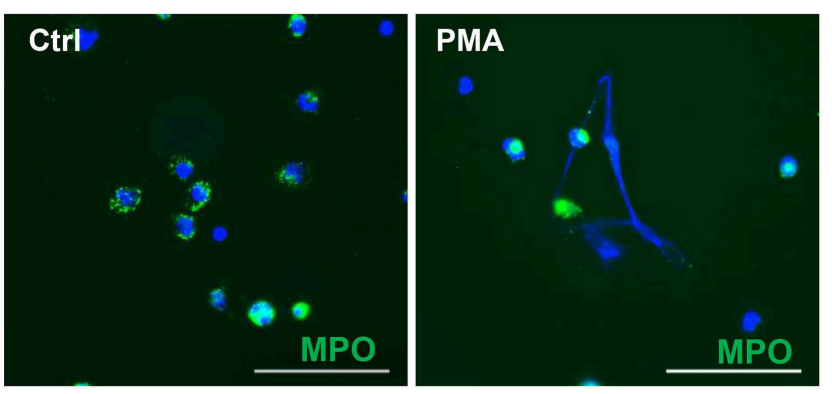

E

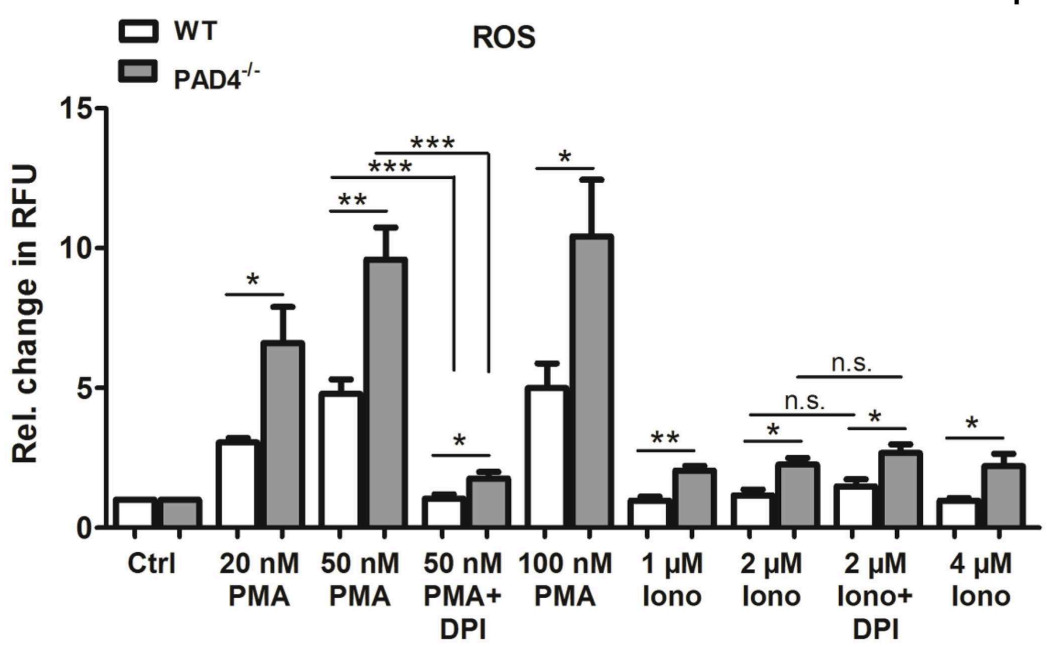

B

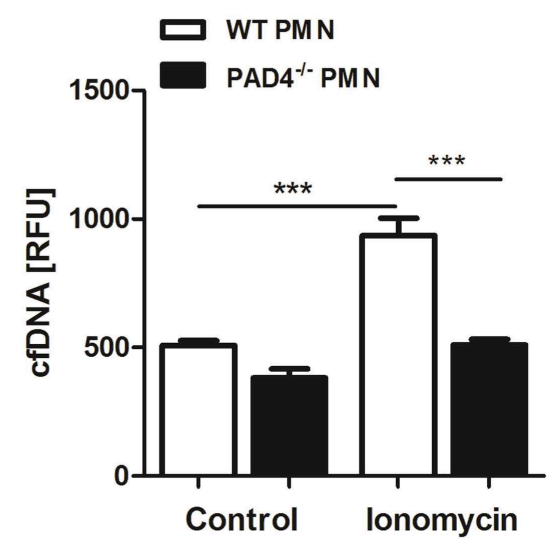

D
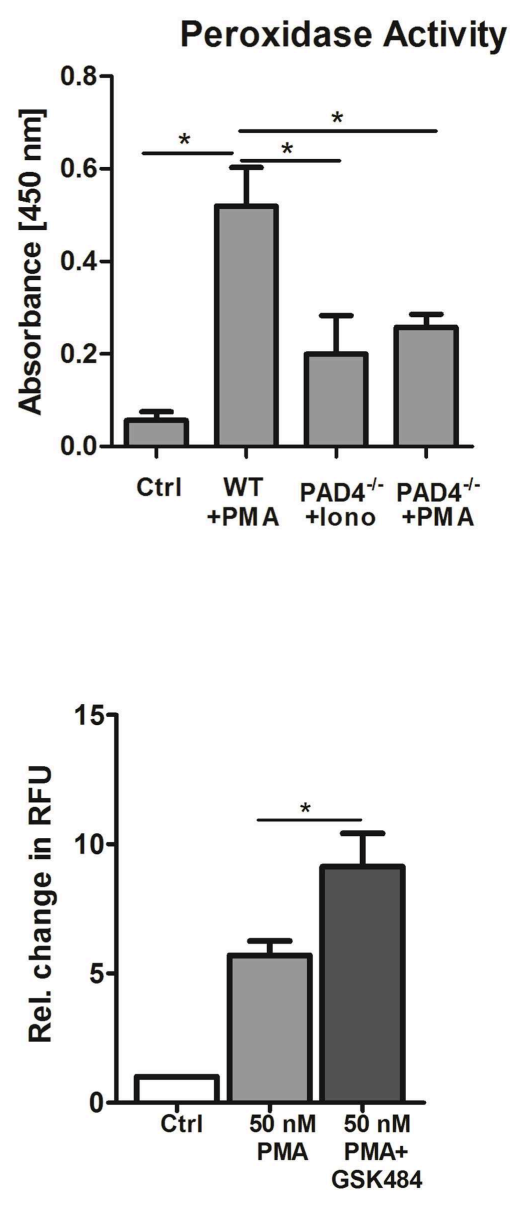

FIGURE 4 | PAD4 $4^{-/-}$neutrophils are unable to release NETs but produce high amounts of ROS. (A) Bone marrow-derived neutrophils from WT and PAD4 ${ }^{-/-}$mice were seeded on coated coverslips and stimulated with $4 \mu \mathrm{M}$ ionomycin for $3 \mathrm{~h}$ at $37^{\circ} \mathrm{C}$. For NETs detection, cells were stained with anti-MPO antibody or anti-citrullinated histone $\mathrm{H} 3$ antibody (both green) and counterstained with DAPI (b/ue). Representative images of five independent experiments are depicted. Scale 
FIGURE 4 | bar $=50 \mu \mathrm{m}$. (B) WT and PAD4 ${ }^{-/-}$neutrophils were stimulated with $4 \mu \mathrm{M}$ ionomycin for $3 \mathrm{~h}$ and cfDNA/NETs release in culture supernatants was quantified by Pico Green DNA staining. $n=5 .{ }^{* \star *} p<0.001$. Two-way ANOVA was performed followed by Newman-Keuls post-hoc test. (C) Bone marrow-derived WT neutrophils were seeded on coverslips and stimulated with $100 \mathrm{nM}$ PMA for $3 \mathrm{~h}$ to release NETs. NETs were detected by staining with anti-MPO antibody (green) and DAPI (b/ue). Representative images of three independent experiments are shown. Arrow heads indicate NETs formation. Scale bar $=50 \mu m$. (D) Peroxidase activity in supernatants collected from WT neutrophils stimulated with PMA (100 nM) and from PAD4 $-/-$ neutrophils stimulated with PMA or ionomycin (4 $\mu$ M), respectively, was quantified by the addition of TMB substrate and absorbance measurement. $n=3$. * $p<0.05$. Two-way ANOVA was performed followed by Newman-Keuls post-hoc test. (E) Bone marrow-derived neutrophils $\left(3 \times 10^{5}\right)$ from WT and PAD4-/- mice were stimulated with the indicated concentrations of PMA and ionomycin for $3 \mathrm{~h}$. In some experiments, cells were pre-incubated with DPI (10 $\mu \mathrm{M})$ for $20 \mathrm{~min}$. Then, DHR-123 (20 $\mu \mathrm{M})$ was added and cells were incubated for additional $15 \mathrm{~min}$ at $37^{\circ} \mathrm{C}$ under shaking. Relative change in RFU compared to unstimulated control samples is depicted. $n=4 .{ }^{*} p<0.05 ;{ }^{* \star} p<0.01 ;{ }^{* \star \star} p<0.001$ determined by the Student $t$-test. (F) Bone marrow-derived WT neutrophils $\left(4 \times 10^{5}\right)$ were pre-cultured in the presence of GSK484 for 20 min before stimulation with $50 \mathrm{nM}$ PMA for $3 \mathrm{~h}$. After addition of DHR-123, cells were further incubated for 15 min under shaking at $37^{\circ} \mathrm{C}$. Fluorescence of Rhodamine- 123 was measured with a microplate reader. Relative change in RFU is depicted. ${ }^{*} p<0.05$ determined by the Student $t$-test.

increased in the infarcted hearts of WT mice. In contrast, significantly higher levels of TNF- $\alpha$ were found in PAD4 ${ }^{-/-}$ hearts at day 1 post-MI, whereby $I L-6$ and $I L-10$ expression were lower than in WT hearts. Both mouse strains showed a significantly higher ratio of $i N O S$ to $\operatorname{Arg} I$, confirming M1 polarization at day 1 post-MI. In addition, the M2a marker $Y m 1$, the M2b markers SPHK1, and LIGHT and the M2c marker MertK markedly increased in infarcted hearts of WT, but not in PAD4 $4^{-/-}$mice (Figure 6B). In accordance with increased MCP-1 plasma levels found in PAD4 ${ }^{-/-}$mice (Figure 5E), FACS analyses revealed enhanced recruitment of $\mathrm{F} 4 / 80^{+}$cells in infarcted PAD4 ${ }^{-/-}$hearts (Figure 6C). Given that NETs also influenced the expression of collagens, the cardiac expression of collagen-1 and -3 was additionally quantified. Notably, the cardiac expression of both genes was significantly upregulated only in WT mice at day 1 post-MI but did not increase in $\mathrm{PAD}^{-/-}$hearts. Similarly, cardiac expression levels of TGF- $\beta$ and MMP-2 were significantly reduced in PAD4-deficient mice when compared to WT mice (Figure 6D). Of note, control $\mathrm{PAD}^{-/-}$mice displayed increased cardiac $M M P-2$ expression when compared to WT mice, suggesting that PAD4 deficiency does not solely influence the formation of NETs.

\section{Increased Acute Inflammation in PAD4-Deficient Mice Does Not Compromise Cardiac Healing and Function in the Post-Acute Phase of MI}

Excessive persistent inflammation was previously described to favor adverse remodeling (38). We therefore investigated whether overwhelming acute inflammation in PAD4 ${ }^{-/-}$mice negatively influences cardiac healing. Consistent with increased cTnT levels, we found slightly increased infarct size in the hearts of PAD4 ${ }^{-/-}$ mice at day 1 when compared to those of WT mice, although not statistically significant (Figure 7A). Of note, although survival rate post-MI was not significantly influenced by the genotype, $\mathrm{PAD}^{-/-}$mice were found to solely die during the acute phase of MI (day 1) and all mice survived at later times (Figure 7B). Remarkably, PAD4 ${ }^{-/-}$mice that survived acute inflammation showed reduced body weight loss and significantly lower heart weight to body weight ratios at day 3 post-MI when compared to WT mice (Figure 7C). Echocardiographic analyses revealed increased end-diastolic volume (EDV) and increased thinning of the left ventricular posterior wall (LVPW) in $\mathrm{PAD}^{-/-}$mice at day 1 , although the left ventricular ejection fraction (LVEF) was not reduced (Figure 7D). Surprisingly, the LVPW was significantly thicker in PAD4 ${ }^{-/-}$hearts already at day 3 post-MI and LVEF was significantly higher at day 21 post-MI. In addition, stroke volume (SV) was slightly increased and the end-diastolic volume (EDV), as well as the left ventricular end-diastolic diameter (LVED), tended to be lower when compared to WT mice, suggesting reduced cardiac hypertrophy and remodeling in this group.

\section{DISCUSSION}

Acute MI leads to the death of cardiomyocytes, which induces the release of DAMPs, including DNA (39), and a strong proinflammatory response, in order to remove the damaged tissue. Numerous previous studies reported that NETs released by activated neutrophils under pathological conditions possess proinflammatory deleterious effects and favor adverse cardiac events (4, 40-44). This study investigated the impact of NETs on macrophage polarization and their role in acute inflammation and cardiac healing post-MI.

As neutrophils persist in the infarcted myocardium for at least 7 days (45) and myocardial macrophages display high plasticity, changing their phenotype from $\mathrm{M} 1$ at day 1 to $\mathrm{M} 2$ at day 7 (11), NETs potentially modulate in vivo macrophage phenotypes. In accordance with the recent study published by Guimarraes-Costa et al. (46), here we found that NETs drive in vitro macrophage polarization toward an anti-inflammatory M2 phenotype under both M1- and M2a-polarizing culture conditions. Under M1-polarizing culture conditions, NETs were found to inhibit IL- 6 and TNF- $\alpha$ expression and to upregulate IL-10 expression in macrophages. Similarly, NETs diminished markers of M2a macrophages in the presence of IL-4, again favoring IL-10 expression. In line with previously reported data (47), we confirm M2 polarization and an increase in IL-10 expression in a TLR-9-dependent manner. In turn, NETs-mediated IL-6 regulation under M1-polarizing conditions seemed to depend on other NETs-associated proteins. The main results of this study are summarized in Figure 8.

To further elaborate NETs effects on acute inflammation and cardiac healing, we used an acute MI model, which has already been reported to provoke cardiac neutrophil recruitment 
A B

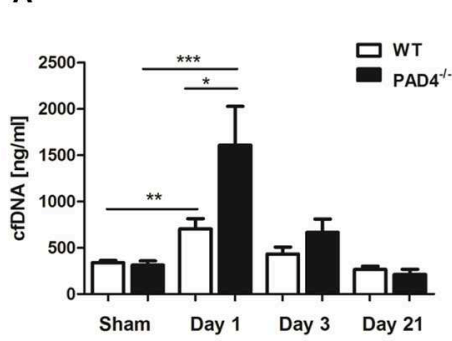

B

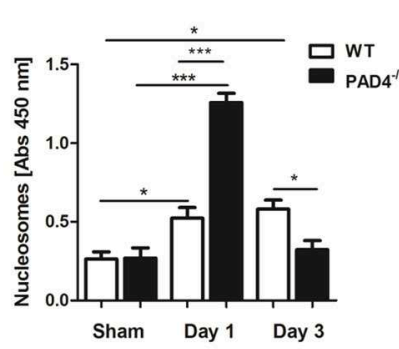

C

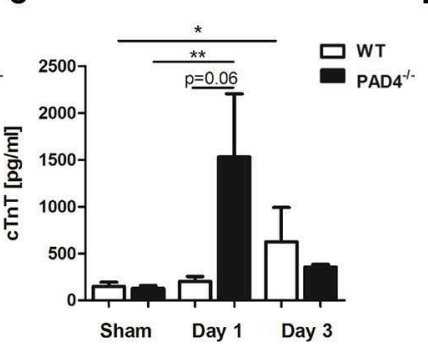

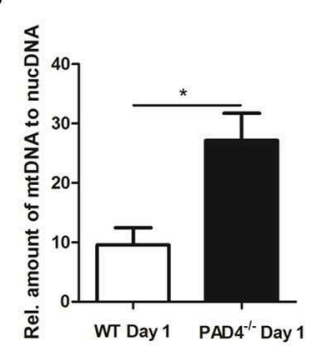

E
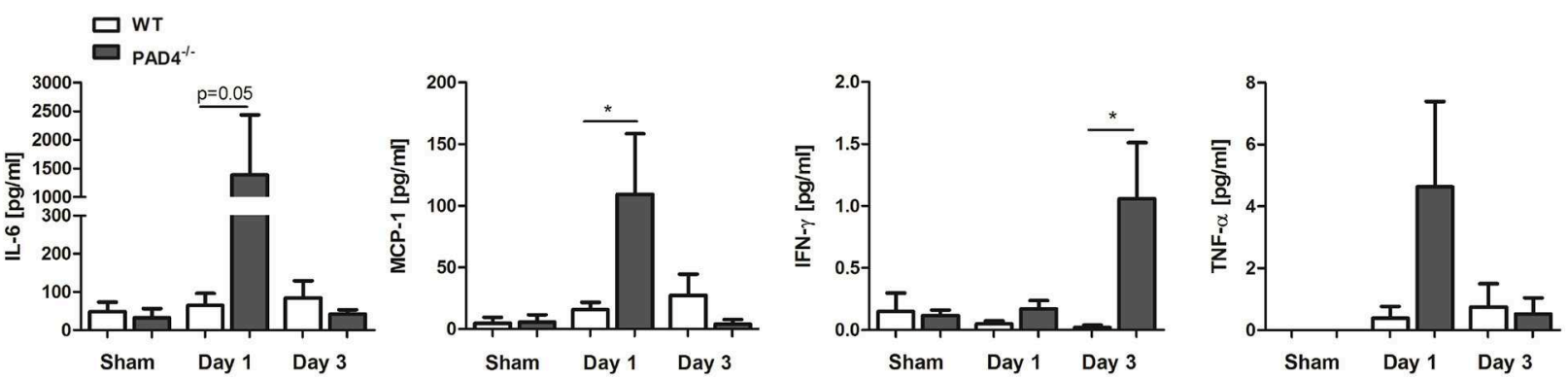

$\mathbf{F}$
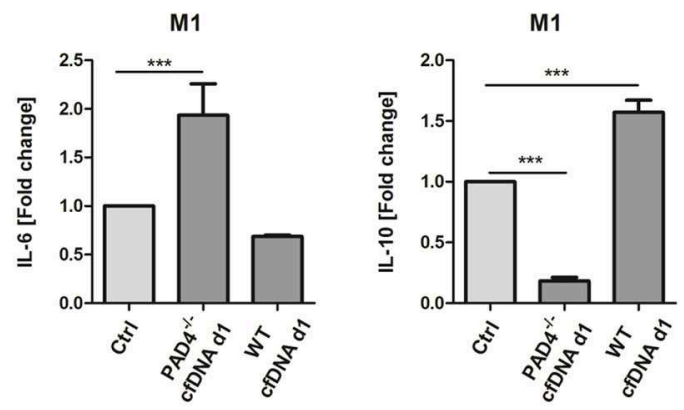

FIGURE 5 | Impact of PAD4-deficiency on the plasma levels of cfDNA, nucleosomes, cardiac troponin and inflammatory markers after MI. cfDNA (A), nucleosomes (B), and cardiac troponin (CTnT) (C) levels were quantified in plasma samples of WT and PAD4-/- mice at day 1 , day 3 , and day 21 after Ml. $n=5-12 .{ }^{*} p<0.05 ;{ }^{* *} p$ $<0.01 ;{ }^{* \star *} p<0.001$. Intra-group differences were determined by two-way ANOVA with Newman-Keuls post-hoc test. For inter-group differences, the Student $t$-test was used. (D) Relative quantification of plasma mtDNA at day 1 post-Ml. $n=5 .{ }^{*} p<0.05$ determined by Student $t$-test. (E) Plasma levels of IL-6, MCP-1, IFN-x, and TNF- $\alpha$ were quantified by ProcartaPlex Multiplex Assay. $n=5-6 .{ }^{*} p<0.05$ determined by the Mann-Whitney test. (F) Macrophages (MO) were cultured under M1-polarizing culture conditions and stimulated with cfDNA $(600 \mathrm{ng} / \mathrm{ml})$ isolated from plasma of WT and PAD4-/- mice at day 1 post-MI. After $24 \mathrm{~h}$, levels of IL-6, and IL-10 were quantified in culture supernatants by ELISA. Fold change in expression vs. unstimulated control cells is depicted. $n=6$. ${ }^{* * *} p<0.001$ determined by two-way ANOVA followed by Newman-Keuls post-hoc test.

and strong release of inflammatory mediators (48). Histone citrullination by PAD4 is known to be necessary for chromatin decondensation during NETosis (49), and PAD4 deficiency was reported to result in the inability of neutrophils to release NETs $(34,50)$. Therefore, PAD4 deficiency should be accompanied by reduced levels of circulating nucleosomes/cfDNA. This assumption was initially supported by Savchenko et al. who found that plasma nucleosome generation in $\mathrm{PAD}^{-/-}$mice was lower than in WT mice in a $24 \mathrm{~h}$ myocardial reperfusion model (4). Having shown that $\mathrm{PAD}^{-/-}$mice display better recovery after $\mathrm{MI}$, the authors concluded that NETs exacerbate ischemia/reperfusion injury. However, we show here for the first time, that PAD4 $4^{-/-}$mice subjected to permanent LAD ligation display significantly higher levels of circulating cfDNA and nucleosomes at day 1 post-MI when compared to WT controls. Thus, circulating nucleosomes/cfDNA do not generally reflect NET release by activated neutrophils and these results strongly contradict impaired cfDNA release in PAD4-deficient mice $(4,43)$ under our experimental conditions.

In our view, the reasons for exacerbated acute inflammatory response post-MI in $\mathrm{PAD} 4^{-/-}$mice seem to be multifaceted. As PAD $4^{-/-}$neutrophils were unable to form NETs ex vivo, 

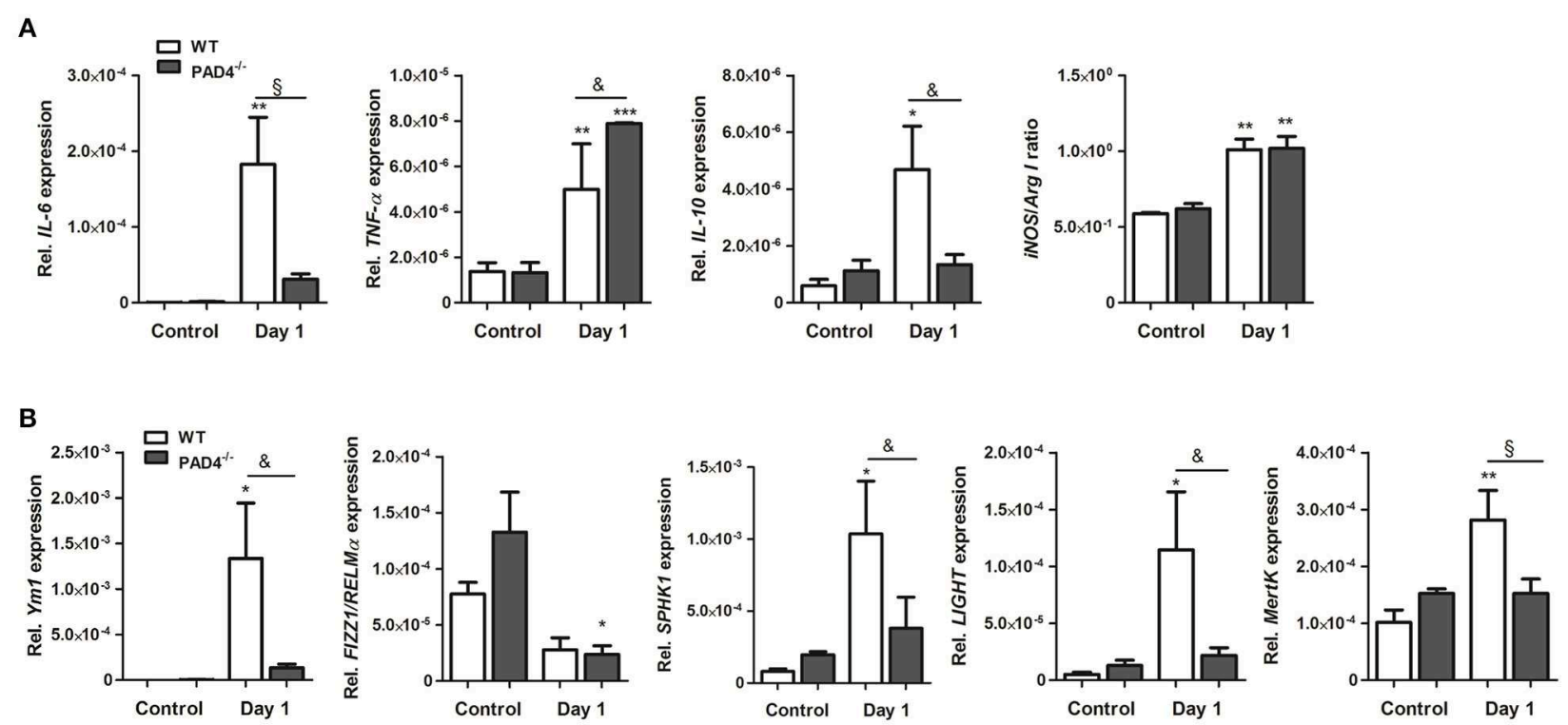

C

D
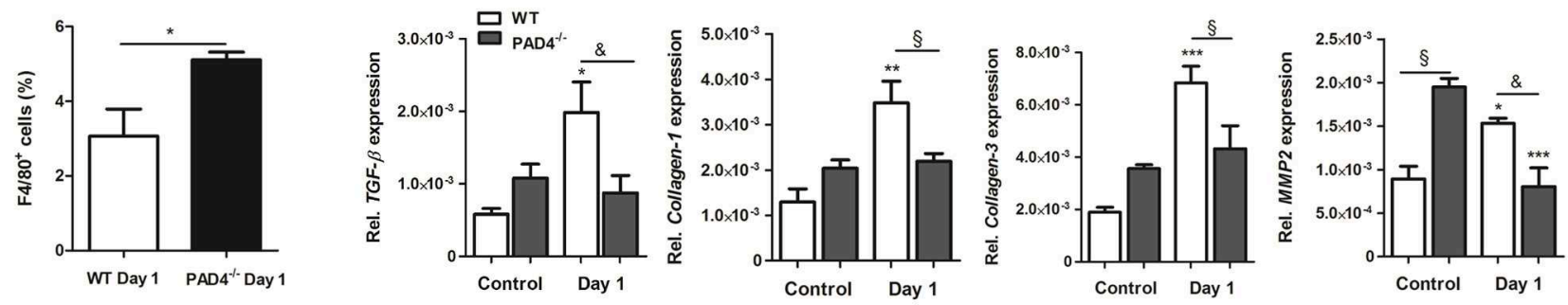

FIGURE 6 | Cardiac expression of inflammation-related genes in PAD4-/- mice at day 1 post-MI. (A) Cardiac gene expression of IL-6, TNF- $\alpha$, IL-10, iNOS, and Arg I was determined by Real time PCR in mice subjected to permanent LAD ligation $(n=3-4)$ and control animals $(n=3-5)$. The ratio of iNOS to Arg / is depicted. (B) To examine polarization toward the M2 phenotype, marker genes specific for the M2a (Ym1, Fizz1/RELM $\alpha$ ), M2b (SPHK1, L/GHT), and M2c (MertK) subtypes were analyzed by Real time PCR. $n=3-5 .{ }^{*} p<0.05 ;{ }^{* *} p<0.01$; ${ }^{* \star \star} p<0.001$ vs. control. ${ }^{\&} p<0.05 ;{ }^{\S} p<0.01$. Two-way ANOVA was performed followed by

Newman-Keuls post-hoc test. (C) Percentage of F $4 / 80^{+}$cells was quantified by flow cytometry in dissociated hearts from WT $(n=3)$ and PAD4-/- $(n=4)$ mice. ${ }^{*} p$ $<0.05$ determined by Student $t$-test. (D) Cardiac expression of TGF-B, Collagen-1, -3 and MMP2 was assessed by Real time PCR. $n=3-5 .{ }^{*} p<0.05 ;{ }^{* *} p<0.01$;

${ }^{* * *} p<0.001$ vs. control. ${ }^{\&} p<0.05 ;{ }^{\S} p<0.01$. Two-way ANOVA was performed followed by Newman-Keuls post-hoc test.

the cfDNA increase found in $\mathrm{PAD} 4^{-/-}$mice is likely to be rather based on massive tissue injury as evidenced by increased plasma levels of cardiac troponin and mtDNA. In line with our assumption, plasma cfDNA isolated from $\mathrm{PAD}^{-/-}$mice at day 1 post-MI was highly pro-inflammatory, and strongly increased IL-6 expression in M1 macrophages. In this regard, TLR-9 activation by mtDNA was shown to provoke systemic inflammation (51), which is supported by the overwhelming pro-inflammatory response and increased mortality in PAD4 ${ }^{-/-}$ mice in the acute phase post-MI.

In addition and in contrast to the data reported by Martinod et al. (52), $\mathrm{PAD}^{-/-}$neutrophils were found to produce higher ROS amounts than WT cells upon in vitro stimulation with PMA and ionomycin, respectively, although they did not release NETs under these conditions. NADPH oxidase inhibition did not abolish ROS production completely, probably due to enhanced production of mitochondrial ROS (53). In line with the findings recently reported (54), we found that PAD4 inhibition in WT neutrophils significantly increases PMAtriggered intracellular ROS production. These results suggest that NADPH oxidase becomes negatively regulated by active PAD4. Therefore, increased inflammation and cardiac injury in $\mathrm{PAD}^{-/-}$mice at day 1 post-MI is likely to be due in part to enhanced ROS release by high number of tissue-infiltrated leukocytes. However, here we failed to quantify lipid peroxidation in infarcted hearts, although no differences were found in plasma samples (unpublished results of our group).

Lastly, due to NETs deficiency in $\mathrm{PAD}^{-/-}$mice, antiinflammatory mechanisms might be delayed, and impaired cardiac function and heart failure reported in neutrophildepleted mice subjected to MI (55) may be attributed to compromised NETs release. Here, we found increased cardiac expression of TNF- $\alpha$ in infarcted hearts of PAD4 ${ }^{-/-}$mice, although $I L-6$ expression was significantly diminished. In this 
A
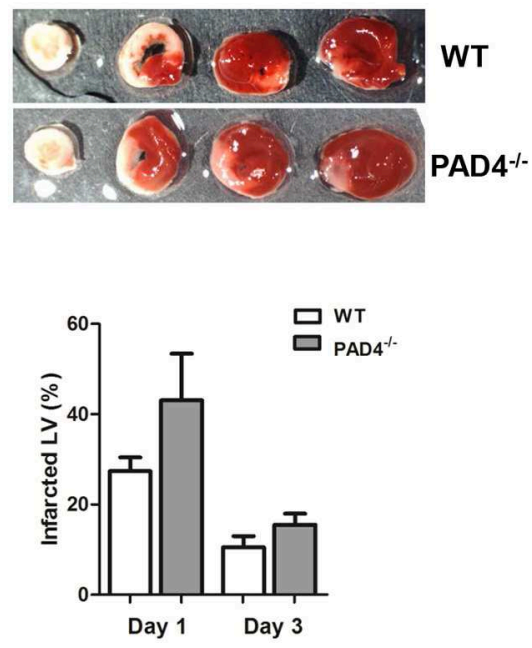

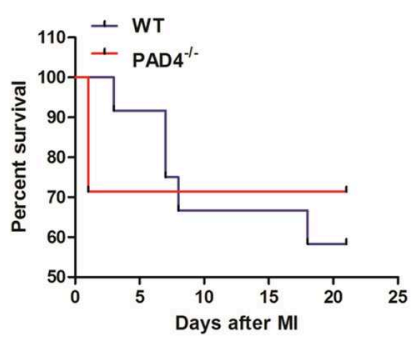

C

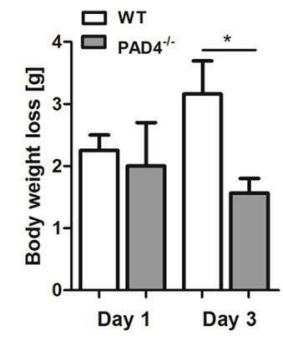

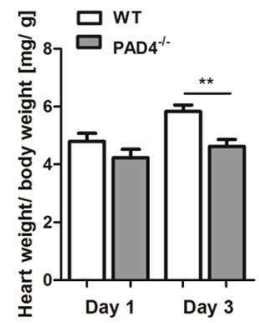

D
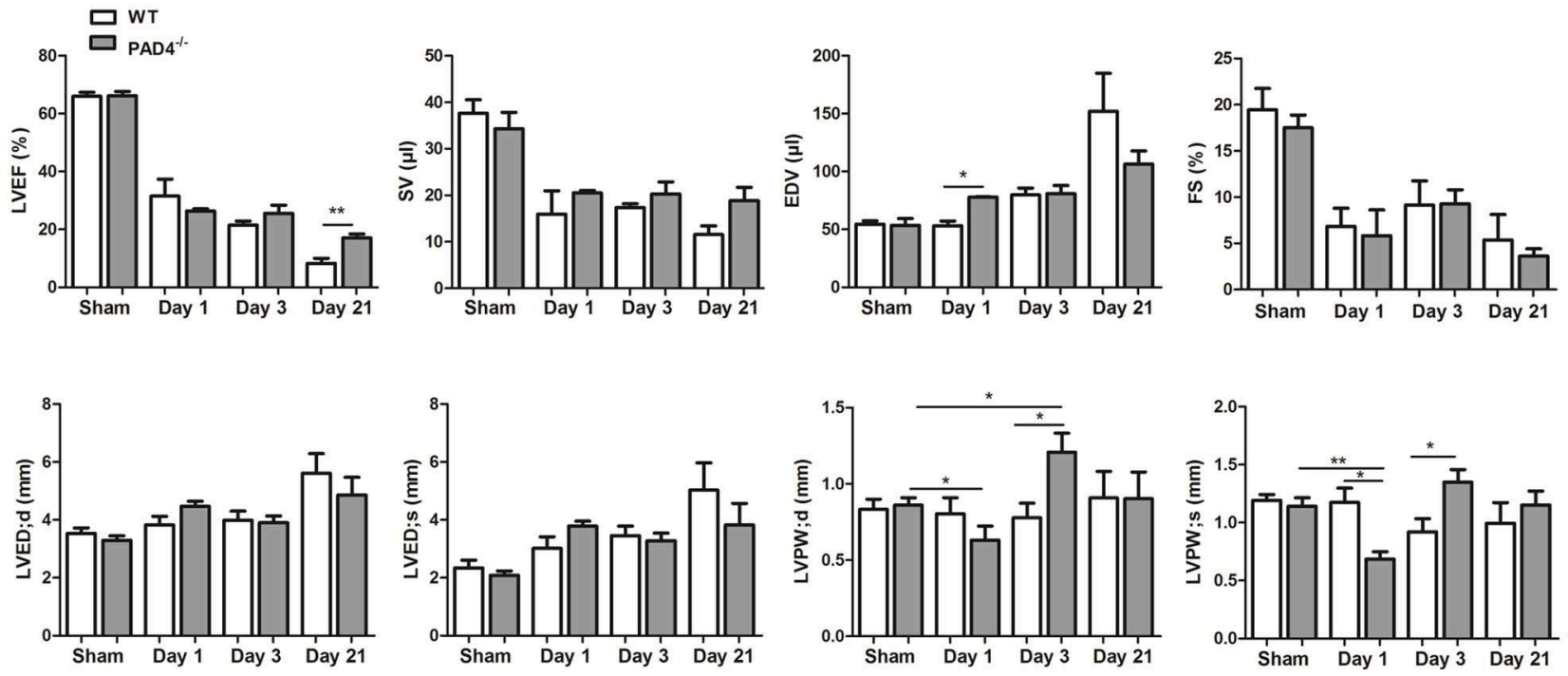

FIGURE 7 | PAD4 ${ }^{-/-}$mice show better recovery at post-acute stages. (A) Quantification of infarct sizes at day 1 ( $n=3$ ) and day $3(n=5)$ post-MI. (B) Survival curves of WT and PAD4-/- mice subjected to permanent LAD ligation for 21 days $(n=7-12)$. (C) Weight loss and heart to body weight ratio in WT and PAD4-/mice at day 1 and day 3 post-MI. $n=3-5$. (D) LVEF, SV, EDV, and FS were determined at days $1(n=3)$, $3(n=8)$, and $21(n=4-5)$ post-MI by transthoracic echocardiography. Additionally, differences in cardiac dimensions (LVED;d, LVED;s, LVPW; d, LVPW;s) between mice were quantified. ${ }^{\star} p<0.05 ;{ }^{\star \star} p<0.01$ determined by Student $t$-test.

respect, we found that NETs upregulate $I L-6$ expression in the cardiac muscle cell line HL-1 (data not shown). Thus, NETs deficiency might be associated with impaired IL-6 production in cardiomyocytes. Because of the pleiotropic nature of this cytokine, it is not clear if reduced IL-6 expression in PAD4 $4^{-/-}$ hearts promotes cardiac repair or aggravates inflammation. However, we recently reported that IL-6 drives polarization toward the M2b phenotype and a strong increase in IL-10 expression (56). Based on these previous results, reduced cardiac IL-6 expression in PAD4 ${ }^{-/}$mice might explain reduced cardiac expression of M2/M2b macrophage markers. In a previous study,
IL-10 expression by cardiac macrophages and fibroblasts has been evidenced (57). As we did not find $I L-10$ expression in cardiac fibroblasts isolated from WT hearts, neither in the absence nor in the presence of NETs (unpublished data), we assume that diminished cardiac $I L-10$ expression in $\mathrm{PAD}^{-/-}$mice at day 1 after MI is indeed due to a reduced number of macrophages expressing M2b markers. Very recently, increased infarct size was reported after PAD4 inhibition with $\mathrm{Cl}$-amidine and permanent ligation in mice. The authors concluded that the pathological process of the permanent ligation model is mainly affected by hypoxia and inflammatory response and speculated that cardiac 


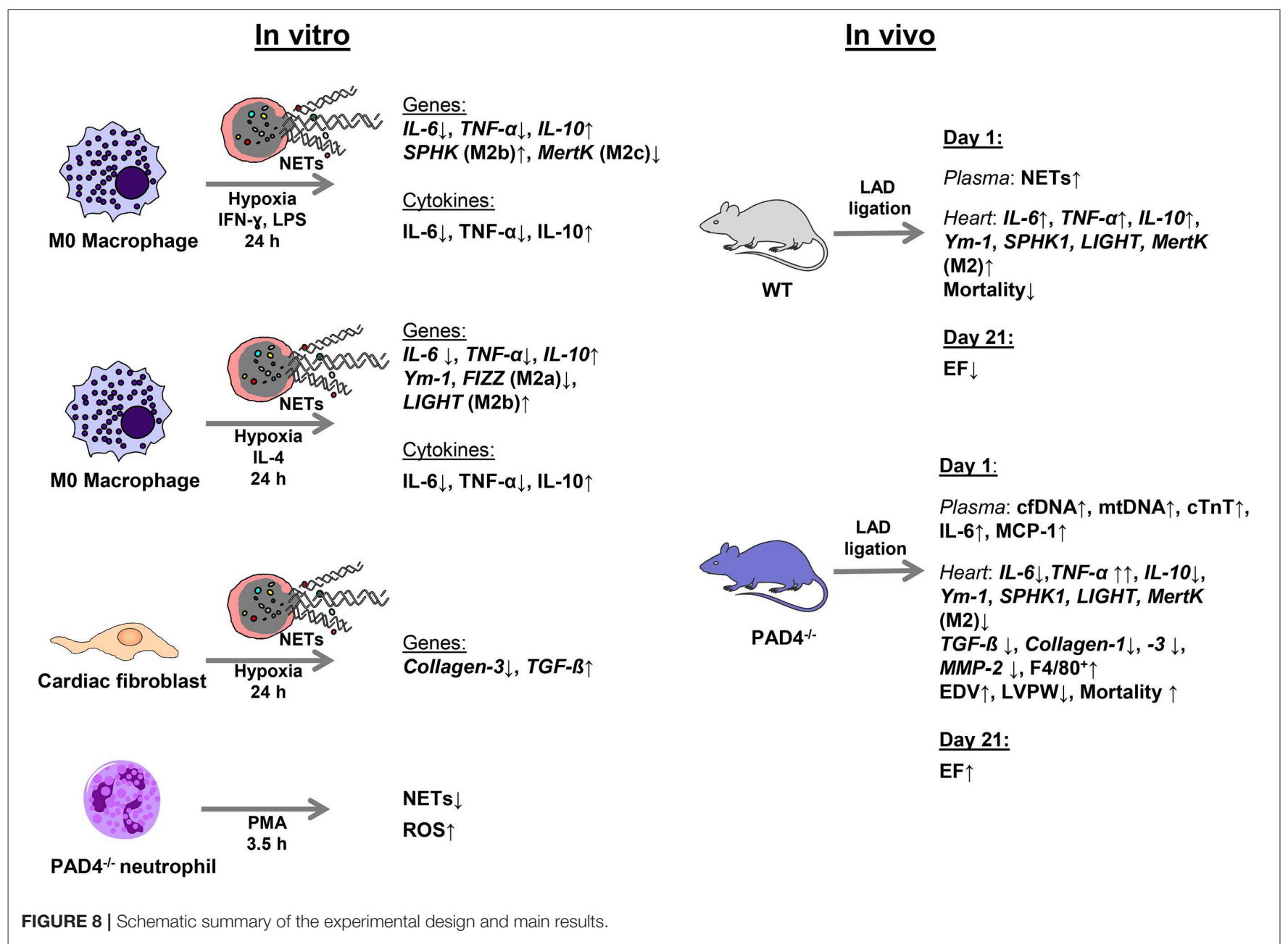

repair requires a proper number of NETs (58). Accordingly, we also found slightly increased infarct sizes in PAD $4^{-/-}$mice at day 1 post-MI. This is probably also in part due to increased $M M P$ 2 expression found in $\mathrm{PAD} 4^{-/-}$mice, which may contribute to enhanced degradation of the extracellular matrix and enhanced infarct expansion (59). Increased thinning of the LVPW and higher EDV further indicate increased ventricular dilatation. However, we did not observe a significant reduction in LVEF at day 1 , probably due to the low number of animals included.

One unexpected finding of this study was that all PAD4 ${ }^{-/-}$ mice survived and displayed improved cardiac function in the post-acute phase (>day 1). In line with the data reported by Hemmers et al. (50), PAD4 ${ }^{-/}$mice showed decreased weight loss already at day 3 post-MI. In addition, thicker LVPW at day 3 post-MI and significantly increased LVEF at day 21 were found when compared to infarcted hearts from WT mice. As $\mathrm{PAD}^{-/-}$mice did not upregulate cardiac TGF- $\beta$ expression at day 1 post-MI, consequently, expression levels of collagen-1, collagen-3, and $M M P-2$ remained reduced when compared to the expression found in WT hearts. Indeed, here, NETs were found to upregulate TGF- $\beta$ expression in cardiac fibroblasts in vitro, which triggers the expression of collagens and MMP-2. However, no upregulation of collagens and $M M P-2$ has been observed in vitro, suggesting a timely delayed regulation. Thus, NETs deficiency accompanied by reduced cardiac TGF- $\beta$ expression might result in moderate collagen deposition, thus increasing ventricular compliance.

However, to prove this assumption, the expression of collagens and MMPs should be monitored over time and the impact on cardiac fibrosis should be evaluated more deeply. In this context, it has already been demonstrated that old PAD4 ${ }^{-/-}$ mice display better LVEF when compared to WT mice, which has been explained by reduced inflammation-related fibrosis. The authors also suggested that NETs drive fibrosis as DNase $I$ infusion delayed the fibrotic process (60). As we demonstrate here that NETs exert anti-inflammatory properties and mice lacking functional PAD4 suffer from strong inflammation and increased mortality in the acute phase of MI, we hypothesize that improved cardiac recovery in the post-acute phase in PAD $4^{-/}$mice is largely based on compensatory mechanisms which cannot simply be explained by the lack of NETs. In line with this, at least two previous studies reported increased IL-10 levels in PAD4 ${ }^{-/-}$mice and concluded that the protective effect of PAD4 deficiency may be related to increased IL-10 production $(43,52)$. The cellular source of IL-10 has not been evaluated, but it was suggested that it might derive from non-NETing 
neutrophils (52). However, we cannot support this assumption as cardiac IL-10 levels at day 1 post-MI, e.g., when the number of cardiac neutrophils is proposed to be very high (45), were found to be significantly lower than in WT mice. Whether IL10 becomes upregulated at later times in $\mathrm{PAD}^{-/-}$mice requires further study. Apart from its role in histone hypercitrullination, PAD4 is involved in gene regulation and PAD4 inhibitors have already been shown to increase $\mathrm{Th}_{2}$ responses (61) and to block the maturation of dendritic cells (62). In view of these multifaceted roles, it can be expected that PAD4 deficiency influences many immune cells and inflammatory pathways yielding in improved cardiac healing and ameliorated adverse remodeling. Importantly, in this pilot study we were not able to study the molecular mechanisms underlying exacerbated acute inflammation in $\mathrm{PAD} 4^{-/-}$mice in more detail, representing a major limitation of this study. Additional analyses are mandatory to explore the effects of NETs deficiency on cardiac macrophage polarization and inflammatory pathways in $\mathrm{PAD} 4^{-/-}$mice.

Altogether, our data suggest that the impaired cardiac upregulation of M2 genes in NETs-deficient mice favors cardiac inflammation in the acute phase after MI. Besides, dysregulated ROS production in PAD4 $4^{-/-}$neutrophils may contribute to increased tissue damage and subsequent cfDNA release in the circulation. We further provide evidence for the proinflammatory action of cfDNA. However, improved cardiac regeneration in PAD4 ${ }^{-/-}$mice has been observed. Studies using PAD4 $4^{-/-}$mice, which aim to assess NETs effects in acute inflammation, should be carefully reviewed as PAD4 deficiency consequentially seems to engage many compensatory mechanisms. Further studies, e.g., based on DNase I infusion, should be conducted to elaborate the role of NETs for cardiac healing and remodeling post-MI in more detail.

\section{DATA AVAILABILITY STATEMENT}

All datasets generated for this study are included in the manuscript/Supplementary Files.

\section{REFERENCES}

1. Laflamme MA, Murry CE. Regenerating the heart. Nat Biotechnol. (2005) 23:845-56. doi: 10.1038/nbt1117

2. Lewis EF, Moye LA, Rouleau JL, Sacks FM, Arnold JM, Warnica JW, et al. Predictors of late development of heart failure in stable survivors of myocardial infarction: the CARE study. J Am Coll Cardiol. (2003) 42:1446-53. doi: 10.1016/S0735-1097(03)01057-X

3. Brill A, Fuchs TA, Savchenko AS, Thomas GM, Martinod K, De Meyer SF, et al. Neutrophil extracellular traps promote deep vein thrombosis in mice. J Thromb Haemost. (2012) 10:136-44. doi: 10.1111/j.1538-7836.2011. 04544.x

4. Savchenko AS, Borissoff JI, Martinod K, De Meyer SF, Gallant M, Erpenbeck L, et al. VWF-mediated leukocyte recruitment with chromatin decondensation by PAD4 increases myocardial ischemia/reperfusion injury in mice. Blood. (2014) 123:141-8. doi: 10.1182/blood-2013-07-514992

5. Warnatsch A, Ioannou M, Wang Q, Papayannopoulos V. Inflammation. Neutrophil extracellular traps license macrophages for cytokine production in atherosclerosis. Science. (2015) 349:316-20. doi: 10.1126/science.aaa8064

\section{ETHICS STATEMENT}

All animal studies were reviewed and approved by the local animal care committee (Bezirksregierung Köln, Germany, No.84-02.04.2014.A234) and complied with the national guidelines for the care and use of laboratory animals.

\section{AUTHOR CONTRIBUTIONS}

AP-G conceived and supervised the study and wrote the manuscript. KE performed surgeries and echocardiographic analyses and interpreted the results. LG performed echocardiographic analyses and in vitro experiments with neutrophils. LG, CW, TL, HZ, UK, and AC performed experiments and analyzed the results. MM and TW provided support with mouse surgeries and echocardiography. All authors participated in data analysis, critically reviewed the manuscript, and gave final approval.

\section{FUNDING}

This study was supported by the Koeln Fortune Program/Faculty of Medicine, University of Cologne (\#214/2016 to AP-G) and the Elisabeth and Rudolf Hirsch Foundation (to KE).

\section{ACKNOWLEDGMENTS}

The authors are very grateful to Dr. Anna Klinke and Senai Bokredenghel for their support with echocardiographic analyses. The authors would like to thank Ms. Sabine Schmitt and Natalia Mierau for excellent technical assistance.

\section{SUPPLEMENTARY MATERIAL}

The Supplementary Material for this article can be found online at: https://www.frontiersin.org/articles/10.3389/fimmu. 2019.02313/full\#supplementary-material
6. Itagaki K, Kaczmarek E, Lee YT, Tang IT, Isal B, Adibnia Y, et al. Mitochondrial DNA released by trauma induces neutrophil extracellular traps. PLOS ONE. (2015) 10:e0120549. doi: 10.1371/journal.pone.0120549

7. Albrengues J, Shields MA, Ng D, Park CG, Ambrico A, Poindexter ME, et al. Neutrophil extracellular traps produced during inflammation awaken dormant cancer cells in mice. Science. (2018) 361:eaao4227. doi: $10.1126 /$ science.aao 4227

8. Ma Y, Yabluchanskiy A, Lindsey ML. Neutrophil roles in left ventricular remodeling following myocardial infarction. Fibrogenesis Tissue Repair. (2013) 6:11. doi: 10.1186/1755-1536-6-11

9. Jolly SR, Kane WJ, Hook BG, Abrams GD, Kunkel SL, Lucchesi BR. Reduction of myocardial infarct size by neutrophil depletion: effect of duration of occlusion. Am Heart J. (1986) 112:682-90. doi: 10.1016/0002-8703(86)90461-8

10. Jung K, Kim P, Leuschner F, Gorbatov R, Kim JK, Ueno T, et al. Endoscopic time-lapse imaging of immune cells in infarcted mouse hearts. Circ Res. (2013) 112:891-9. doi: 10.1161/CIRCRESAHA.111.300484

11. Mouton AJ, DeLeon-Pennell KY, Rivera Gonzalez OJ, Flynn ER, Freeman TC, Saucerman JJ, et al. Mapping macrophage polarization over the 
myocardial infarction time continuum. Basic Res Cardiol. (2018) 113:26. doi: 10.1007/s00395-018-0686-x

12. Ma Y, Halade GV, Zhang J, Ramirez TA, Levin D, Voorhees A, et al. Matrix metalloproteinase-28 deletion exacerbates cardiac dysfunction and rupture after myocardial infarction in mice by inhibiting M2 macrophage activation. Circ Res. (2013) 112:675-88. doi: 10.1161/CIRCRESAHA.111.300502

13. Yue Y, Yang X, Feng K, Wang L, Hou J, Mei B, et al. M2b macrophages reduce early reperfusion injury after myocardial ischemia in mice: a predominant role of inhibiting apoptosis via A20. Int J Cardiol. (2017) 245:228-35. doi: 10.1016/j.ijcard.2017.07.085

14. Courties G, Heidt T, Sebas M, Iwamoto Y, Jeon D, Truelove J, et al. In vivo silencing of the transcription factor IRF5 reprograms the macrophage phenotype and improves infarct healing. J Am Coll Cardiol. (2014) 63:155666. doi: 10.1016/j.jacc.2013.11.023

15. Porter KE, Turner NA. Cardiac fibroblasts: at the heart of myocardial remodeling. Pharmacol Ther. (2009) 123:255-78. doi: $10.1016 /$ j.pharmthera.2009.05.002

16. Chrysanthopoulou A, Mitroulis I, Apostolidou E, Arelaki S, Mikroulis D, Konstantinidis $\mathrm{T}$, et al. Neutrophil extracellular traps promote differentiation and function of fibroblasts. J Pathol. (2014) 233:294-307. doi: $10.1002 /$ path.4359

17. Weber KT, Sun Y, Bhattacharya SK, Ahokas RA, Gerling IC. Myofibroblastmediated mechanisms of pathological remodelling of the heart. Nat Rev Cardiol. (2013) 10:15-26. doi: 10.1038/nrcardio.2012.158

18. Bauer M, Cheng S, Jain M, Ngoy S, Theodoropoulos C, Trujillo A, et al. Echocardiographic speckle-tracking based strain imaging for rapid cardiovascular phenotyping in mice. Circ Res. (2011) 108:908-16. doi: 10.1161/CIRCRESAHA.110.239574

19. Paunel-Gorgulu A, Wacker M, El Aita M, Hassan S, Schlachtenberger G, Deppe A, et al. cfDNA correlates with endothelial damage after cardiac surgery with prolonged cardiopulmonary bypass and amplifies NETosis in an intracellular TLR9-independent manner. Sci Rep. (2017) 7:17421. doi: 10.1038/s41598-017-17561-1

20. Jin Y, Liu Y, Nelin LD. Extracellular signal-regulated kinase mediates expression of arginase II but not inducible nitric-oxide synthase in lipopolysaccharide-stimulated macrophages. J Biol Chem. (2015) 290:2099111. doi: 10.1074/jbc.M114.599985

21. Davis MJ, Tsang TM, Qiu Y, Dayrit JK, Freij JB, Huffnagle GB, et al. Macrophage M1/M2 polarization dynamically adapts to changes in cytokine microenvironments in Cryptococcus neoformans infection. MBio. (2013) 4:e00264-13. doi: 10.1128/mBio.00264-13

22. Yeh $\mathrm{CH}$, Cho W, So EC, Chu CC, Lin MC, Wang JJ, et al. Propofol inhibits lipopolysaccharide-induced lung epithelial cell injury by reducing hypoxia-inducible factor-1alpha expression. Br J Anaesth. (2011) 106:590-9. doi: 10.1093/bja/aer005

23. Horber S, Hildebrand DG, Lieb WS, Lorscheid S, Hailfinger S, Schulze-

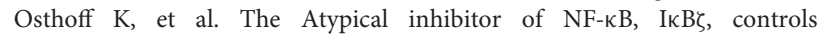
macrophage interleukin-10 expression. J Biol Chem. (2016) 291:12851-61. doi: 10.1074/jbc.M116.718825

24. Huang XR, Chung AC, Wang XJ, Lai KN, Lan HY. Mice overexpressing latent TGF-betal are protected against renal fibrosis in obstructive kidney disease. Am J Physiol Renal Physiol. (2008) 295:F118-127. doi: 10.1152/ajprenal.00021.2008

25. Tong Z, Chen R, Alt DS, Kemper S, Perbal B, Brigstock DR. Susceptibility to liver fibrosis in mice expressing a connective tissue growth factor transgene in hepatocytes. Hepatology. (2009) 50:939-47. doi: 10.1002/hep.23102

26. Castrillo A, Joseph SB, Marathe C, Mangelsdorf DJ, Tontonoz P. Liver X receptor-dependent repression of matrix metalloproteinase- 9 expression in macrophages. J Biol Chem. (2003) 278:10443-9. doi: 10.1074/jbc.M213071200

27. $\mathrm{Wu} \mathrm{F}$, Chakravarti S. Differential expression of inflammatory and fibrogenic genes and their regulation by NF-kappaB inhibition in a mouse model of chronic colitis. J Immunol. (2007) 179:6988-7000. doi: 10.4049/jimmunol.179.10.6988

28. Tatano Y, Shimizu T, Tomioka H. Unique macrophages different from M1/M2 macrophages inhibit $\mathrm{T}$ cell mitogenesis while upregulating Th17 polarization. Sci Rep. (2014) 4:4146. doi: 10.1038/srep04146

29. Clark K, MacKenzie KF, Petkevicius K, Kristariyanto Y, Zhang J, Choi HG, et al. Phosphorylation of CRTC3 by the salt-inducible kinases controls the interconversion of classically activated and regulatory macrophages. Proc Natl Acad Sci USA. (2012) 109:16986-91. doi: 10.1073/pnas.1215450109

30. Galvan MD, Foreman DB, Zeng E, Tan JC, Bohlson SS. Complement component $\mathrm{Clq}$ regulates macrophage expression of Mer tyrosine kinase to promote clearance of apoptotic cells. J Immunol. (2012) 188:3716-23. doi: 10.4049/jimmunol.1102920

31. Wu B, Ni H, Li J, Zhuang X, Zhang J, Qi Z, et al. The impact of circulating mitochondrial DNA on cardiomyocyte apoptosis and myocardial injury after TLR4 activation in experimental autoimmune myocarditis. Cell Physiol Biochem. (2017) 42:713-28. doi: 10.1159/000477889

32. Cheng Y, Rong J. Macrophage polarization as a therapeutic target in myocardial infarction. Curr Drug Targets. (2018) 19:651-62. doi: 10.2174/1389450118666171031115025

33. Khabbazi S, Goumon Y, Parat MO. Morphine modulates interleukin-4- or breast cancer cell-induced pro-metastatic activation of macrophages. Sci Rep. (2015) 5:11389. doi: 10.1038/srep11389

34. Li P, Li M, Lindberg MR, Kennett MJ, Xiong N, Wang Y. PAD4 is essential for antibacterial innate immunity mediated by neutrophil extracellular traps. J Exp Med. (2010) 207:1853-62. doi: 10.1084/jem.201 00239

35. Marsman G, Zeerleder S, Luken BM. Extracellular histones, cell-free DNA, or nucleosomes: differences in immunostimulation. Cell Death Dis. (2016) 7:e2518. doi: 10.1038/cddis.2016.410

36. Chistiakov DA, Orekhov AN, Bobryshev YV. The role of cardiac fibroblasts in post-myocardial heart tissue repair. Exp Mol Pathol. (2016) 101:231-40. doi: 10.1016/j.yexmp.2016.09.002

37. Spinale FG. Myocardial matrix remodeling and the matrix metalloproteinases: influence on cardiac form and function. Physiol Rev. (2007) 87:1285-342. doi: 10.1152/physrev.00012.2007

38. Deswal A, Petersen NJ, Feldman AM, Young JB, White BG, Mann DL. Cytokines and cytokine receptors in advanced heart failure: an analysis of the cytokine database from the Vesnarinone trial (VEST). Circulation. (2001) 103:2055-9. doi: 10.1161/01.CIR.103.16.2055

39. Destouni A, Vrettou C, Antonatos D, Chouliaras G, Traeger-Synodinos J, Patsilinakos S, et al. Cell-free DNA levels in acute myocardial infarction patients during hospitalization. Acta Cardiol. (2009) 64:51-7. doi: 10.2143/AC.64.1.2034362

40. Martinod K, Demers M, Fuchs TA, Wong SL, Brill A, Gallant M, et al. Neutrophil histone modification by peptidylarginine deiminase 4 is critical for deep vein thrombosis in mice. Proc Natl Acad Sci USA. (2013) 110:8674-9. doi: 10.1073/pnas.1301059110

41. Mangold A, Alias S, Scherz T, Hofbauer T, Jakowitsch J, Panzenbock A, et al. Coronary neutrophil extracellular trap burden and deoxyribonuclease activity in ST-elevation acute coronary syndrome are predictors of ST-segment resolution and infarct size. Circ Res. (2015) 116:1182-92. doi: 10.1161/CIRCRESAHA.116.304944

42. Pertiwi KR, van der Wal AC, Pabittei DR, Mackaaij C, van Leeuwen MB, Li X, et al. Neutrophil extracellular traps participate in all different types of thrombotic and haemorrhagic complications of coronary atherosclerosis. Thromb Haemost. (2018) 118:1078-87. doi: 10.1055/s-0038-1641749

43. Raup-Konsavage WM, Wang Y, Wang WW, Feliers D, Ruan H, Reeves WB. Neutrophil peptidyl arginine deiminase-4 has a pivotal role in ischemia/reperfusion-induced acute kidney injury. Kidney Int. (2018) 93:36574. doi: 10.1016/j.kint.2017.08.014

44. Wang X, Yang D, Liu J, Fan X, Ma A, Liu P. Prognostic value of culprit artery double-stranded DNA in ST-segment elevated myocardial infarction. Sci Rep. (2018) 8:9294. doi: 10.1038/s41598-018-27639-Z

45. Ma Y, Yabluchanskiy A, Iyer RP, Cannon PL, Flynn ER, Jung M, et al. Temporal neutrophil polarization following myocardial infarction. Cardiovasc Res. (2016) 110:51-61. doi: 10.1093/cvr/cvw024

46. Guimaraes-Costa AB, Rochael NC, Oliveira F, Echevarria-Lima J, Saraiva EM. Neutrophil extracellular traps reprogram IL-4/GM-CSF-induced monocyte differentiation to anti-inflammatory macrophages. Front Immunol. (2017) 8:523. doi: 10.3389/fimmu.2017.00523

47. Celhar T, Pereira-Lopes S, Thornhill SI, Lee HY, Dhillon MK, Poidinger $\mathrm{M}$, et al. TLR7 and TLR9 ligands regulate antigen presentation by macrophages. Int Immunol. (2016) 28:223-32. doi: 10.1093/intimm/d xv066 
48. Hashmi S, Al-Salam S. Acute myocardial infarction and myocardial ischemiareperfusion injury: a comparison. Int J Clin Exp Pathol. (2015) 8:8786-96. Available online at: http://www.ijcep.com/files/ijcep0011868.pdf

49. Wang Y, Li M, Stadler S, Correll S, Li P, Wang D, et al. Histone hypercitrullination mediates chromatin decondensation and neutrophil extracellular trap formation. J Cell Biol. (2009) 184:205-13. doi: $10.1083 /$ jcb. 200806072

50. Hemmers S, Teijaro JR, Arandjelovic S, Mowen KA. PAD4mediated neutrophil extracellular trap formation is not required for immunity against influenza infection. PLoS ONE. (2011) 6:e22043. doi: 10.1371/journal.pone.0022043

51. Collins LV, Hajizadeh S, Holme E, Jonsson IM, Tarkowski A. Endogenously oxidized mitochondrial DNA induces in vivo and in vitro inflammatory responses. J Leukoc Biol. (2004) 75:995-1000. doi: 10.1189/jlb.07 03328

52. Martinod K, Fuchs TA, Zitomersky NL, Wong SL, Demers M, Gallant $\mathrm{M}$, et al. PAD4-deficiency does not affect bacteremia in polymicrobial sepsis and ameliorates endotoxemic shock. Blood. (2015) 125:1948-56. doi: 10.1182/blood-2014-07-587709

53. Douda DN, Khan MA, Grasemann H, Palaniyar N. SK3 channel and mitochondrial ROS mediate NADPH oxidase-independent NETosis induced by calcium influx. Proc Natl Acad Sci USA. (2015) 112:2817-22. doi: 10.1073/pnas.1414055112

54. Zhou Y, An LL, Chaerkady R, Mittereder N, Clarke L, Cohen TS, et al. Evidence for a direct link between PAD4-mediated citrullination and the oxidative burst in human neutrophils. Sci Rep. (2018) 8:15228. doi: 10.1038/s41598-018-33385-z

55. Horckmans M, Ring L, Duchene J, Santovito D, Schloss MJ, Drechsler M, et al. Neutrophils orchestrate post-myocardial infarction healing by polarizing macrophages towards a reparative phenotype. Eur Heart J. (2017) 38:187-97. doi: 10.1093/eurheartj/ehw002

56. Philipp D, Suhr L, Wahlers T, Choi YH, Paunel-Gorgulu A. Preconditioning of bone marrow-derived mesenchymal stem cells highly strengthens their potential to promote IL-6-dependent M2b polarization. Stem Cell Res Ther. (2018) 9:286. doi: 10.1186/s13287-018-1039-2
57. Hulsmans M, Sager HB, Roh JD, Valero-Munoz M, Houstis NE, Iwamoto Y, et al. Cardiac macrophages promote diastolic dysfunction. J Exp Med. (2018) 215:423-40. doi: 10.1084/jem.20171274

58. Zhou Z, Zhang S, Ding S, Abudupataer M, Zhang Z, Zhu X, et al. Excessive neutrophil extracellular trap formation aggravates acute myocardial infarction injury in apolipoprotein E deficiency mice via the ROS-dependent pathway. Oxid Med Cell Longev. (2019) 2019:1209307. doi: 10.1155/2019/1209307

59. Nilsson L, Hallen J, Atar D, Jonasson L, Swahn E. Early measurements of plasma matrix metalloproteinase-2 predict infarct size and ventricular dysfunction in ST-elevation myocardial infarction. Heart. (2012) 98:31-6. doi: 10.1136/heartjnl-2011-300079

60. Martinod K, Witsch T, Erpenbeck L, Savchenko A, Hayashi H, Cherpokova D, et al. Peptidylarginine deiminase 4 promotes age-related organ fibrosis. J Exp Med. (2017) 214:439-58. doi: 10.1084/jem.20160530

61. Kawalkowska J, Quirke AM, Ghari F, Davis S, Subramanian V, Thompson $\mathrm{PR}$, et al. Abrogation of collagen-induced arthritis by a peptidyl arginine deiminase inhibitor is associated with modulation of T cell-mediated immune responses. Sci Rep. (2016) 6:26430. doi: 10.1038/srep26430

62. Jang B, Kim HW, Kim JS, Kim WS, Lee BR, Kim S, et al. Peptidylarginine deiminase inhibition impairs Toll-like receptor agonist-induced functional maturation of dendritic cells, resulting in the loss of $\mathrm{T}$ cell-proliferative capacity: a partial mechanism with therapeutic potential in inflammatory settings. J Leukoc Biol. (2015) 97:351-62. doi: 10.1189/jlb.3A0314-142RR

Conflict of Interest: The authors declare that the research was conducted in the absence of any commercial or financial relationships that could be construed as a potential conflict of interest.

Copyright (c) 2019 Eghbalzadeh, Georgi, Louis, Zhao, Keser, Weber, Mollenhauer, Conforti, Wahlers and Paunel-Görgülü. This is an open-access article distributed under the terms of the Creative Commons Attribution License (CC BY). The use, distribution or reproduction in other forums is permitted, provided the original author(s) and the copyright owner(s) are credited and that the original publication in this journal is cited, in accordance with accepted academic practice. No use, distribution or reproduction is permitted which does not comply with these terms. 